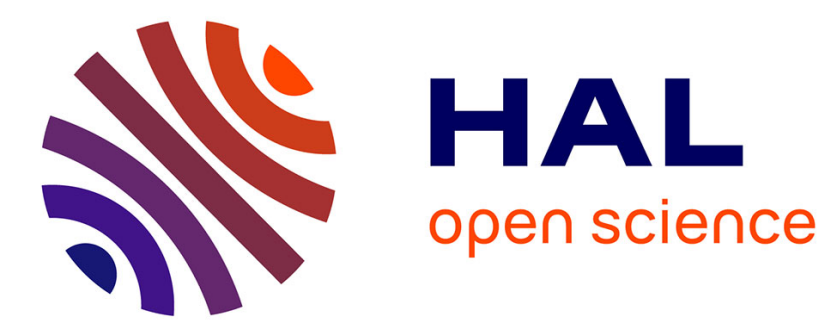

\title{
De l'exploitation des chevaux aux stratégies de subsistance des Magdaléniens du Bassin parisien
}

Olivier Bignon

\section{To cite this version:}

Olivier Bignon. De l'exploitation des chevaux aux stratégies de subsistance des Magdaléniens du Bassin parisien. Gallia Préhistoire - Archéologie de la France préhistorique, 2006, 48, pp.181-206. 10.3406/galip.2006.2450 . hal-02345776

\section{HAL Id: hal-02345776 \\ https://hal.science/hal-02345776}

Submitted on 16 Jan 2020

HAL is a multi-disciplinary open access archive for the deposit and dissemination of scientific research documents, whether they are published or not. The documents may come from teaching and research institutions in France or abroad, or from public or private research centers.
L'archive ouverte pluridisciplinaire HAL, est destinée au dépôt et à la diffusion de documents scientifiques de niveau recherche, publiés ou non, émanant des établissements d'enseignement et de recherche français ou étrangers, des laboratoires publics ou privés.

\section{(ㅇ)(1) $\$$}

Distributed under a Creative Commons Attribution - NonCommercial - NoDerivatives 44.0 


\title{
DE L'EXPLOITATION DES CHEVAUX
}

\section{AUX STRATÉGIES DE SUBSISTANCE DES MAGDALÉNIENS DU BASSIN PARISIEN}

\author{
Olivier BIGNON*
}

\begin{abstract}
Mots-clés. Magdalénien, Bassin parisien, chevaux, saisonnalité, exploitation animale, tactique de chasse, stratégie de chasse.
Résumé. Le Magdalénien du Bassin parisien a encore l'image d'une société à l'économie de subsistance principalement fondée sur la chasse en masse du renne. Pourtant, depuis le début des années 1990, plusieurs gisements situés à Marolles-sur-Seine tendent à relativiser cette vision. En effet, dans les différents secteurs du Tureau des Gardes et au Grand Canton, les chevaux semblent avoir été chassés préférentiellement par les groupes magdaléniens. L'étude archéozoologique des vestiges de chevaux découverts dans les sites magdaléniens du Bassin parisien a permis de caractériser l'exploitation de ces équidés. Les résultats mettent en lumière l'élaboration de différentes tactiques de chasse et l'importance des contextes topographique et géographique de Marolles-sur-Seine. La reconstitution des objectifs liés à l'exploitation des chevaux amène à mieux saisir les stratégies de subsistance des Magdaléniens. Malgré des difficultés au niveau de la résolution chronologique des sites du Bassin parisien dues au plateau radiocarbone du Bölling, nos observations permettent de discuter les grands modèles d'occupation territoriale et d'évolution culturelle. Ce faisant, il est possible d'envisager le mode de vie de ces groupes magdaléniens, en termes de morphologie sociale et de mobilité.
\end{abstract}

Key-words. Magdalenian, Paris Basin, horses, seasonality, animal exploitation, hunting tactic, hunting strategy.

Abstract. The Magdalenian of the Paris Basin still has the image of a subsistence economy society principally based on deer hunting. However, since the early 1990's, several open sites situated at Marolles-sur-Seine, tend to relativize this view. In different areas of the Tureau des Gardes and of the Grand Canton, horses seem to have mainly been hunted by Magdalenian groups. The archaeozoological study of horse remains in Magdalenian sites of the Paris Basin made possible the characterization of the equidae exploitation. Results bring to light the elaboration of varied hunting tactics and the importance of topographical and geographical environments of Marollessur-Seine. The reconstruction of the objectives connected to horse exploitation allows a better understanding of the subsistence strategy of the Magdalenians. Despite the problems related to the chronological resolution of the sites of the Parisian Basin due to the Bolling radiocarbone plateau, it is possible through our observations to discuss the models of territory occupation and of cultural evolution. So, now we can consider the lifeway of these Magdalenian bands in terms of social morphology and of mobility.

Palabras claves. Magdaleniense, Bassin parisien, caballos, estacionalidad, explotación animal, tácticas de cacería, estrategias de cacería.

Resumen. Todavía sigue vigente la visión del magdaleniense del Bassin parisien como una sociedad cuya economía de subsistencia fue principalmente sustentada por la cacería masiva del reno. Sin embargo, desde el inicio de los noventas, la excavación de varios yacimientos ubicados en Marolles-sur-Seine ha matizado esta imagen. En varios sectores de Tureau des Gardes y de Grand Canton, el caballo parece haber sido cazado de forma preferencial por los magdalenienses. El análisis arqueozoológico de los restos de caballo encontrados en los sitios del Bassin parisien ha permitido definir el uso de los équidos. Los resultados obtenidos revelan la existencia de varias técnicas de cacería y la importancia topográfica y geográfica de Marolles-sur-Seine. La reconstitución de los objetivos relacionados de esta explotación de los caballos permite discernir mejor las estrategias de subsistencia de los magdalenienses. A pesar de los problemas cronológico de los sitios del Bassin parisien, que se deben al plateau radiocarbono del Bölling, nuestras observaciones abren una discusión sobre los grandes modelos del patrón de asentamiento y de la evolución cultural. Es entonces posible considerar el modo de vida de los magdalenienses según los criterios de morfología social y de movilidad.

Traducido por Gregory PEREIRA

* UMR 5197 du CNRS, "Archéozoologie, histoire des sociétés humaines et des peuplements animaux ", Muséum national d'histoire naturelle, 55 rue Buffon, F-75231 Paris Cedex 05. 
En tant que société, les Magdaléniens s'inscrivent dans le contexte climatique et environnemental instable du Tardiglaciaire, dans le temps (15 000 à $10000 \mathrm{BP}$ ) comme dans l'espace (Magny, 1995; Stuiver et al., 1995, 1998; Björck et al., 1998; Coope et al., 1998). En tant qu'espèce, ces hommes peuvent être considérés comme un superprédateur au sein des peuplements très diversifiés de la «steppe à mammouth» (Guthrie, 1982, 1984, 1990). Si cette dernière connaît une certaine variabilité dans ses associations taxonomiques régionales en Eurasie (Hopkins et al., 1982; Eriksen, 1996 ; Bridault, Chaix, 2002; Bignon, 2003), cela est vraisemblablement dû aux caractéristiques locales de paysages en mosaïque (Guthrie, ibid.). Ce type de structuration de l'environnement est à mettre en relation avec les particularités régionales, indépendamment du positionnement latitudinal: les variations semblent plutôt liées aux contextes topographiques et hydrographiques, ainsi qu'aux contrastes thermiques (Coope, et al., 1998). Ainsi, on peut concevoir les peuplements régionaux de la «steppe à mammouth » comme des laboratoires de l'évolution, relativement indépendants les uns des autres. En témoigne la fragmentation des populations de rennes en Europe occidentale (Enloe, 1994; Weinstock, 1997; Fontana, 2000), de même que celle des chevaux (Bignon et al., 2005; Bignon, Eisenmann, 2006). Or, les mammouths, les rennes, les chevaux et les bisons sont des composantes fondamentales des communautés animales de la «steppe à mammouth » au Paléolithique supérieur en Eurasie (Hopkins et al., 1998; Guthrie, 1982). Faut-il donc s'étonner de voir émerger des faciès régionaux au Magdalénien (Rigaud et al., 1992; Otte, 1992; Djindjian, 2000), et que leurs activités de subsistance s'attachent plus particulièrement à ces espèces animales? Dans tous les cas, dans le Bassin parisien, la «steppe à mammouth » semble disparaître à la fin du Bölling ou au Dryas II (vers 12 000-11 800 BP; Bignon, 2003). Cela coïncide avec le moment où l'occupation régionale du Magdalénien ne laisse plus de trace (Valentin, Pigeot, 2000), mais il serait prématuré d'en tirer un lien de cause à effet en l'état actuel des recherches.

Cet article a pour but d'offrir une vision synthétique des derniers travaux archéozoologiques portant sur le Magdalénien du Bassin parisien (Bignon, 2003). Ces études apportent une nouvelle vision des stratégies de subsistance et du mode de vie des groupes magdaléniens, en se fondant principalement sur les tactiques de chasse aux chevaux. Le développement des observations paléodémographiques, associées à l'estimation de la saisonnalité d'abattage de ces grands gibiers, permet d'éclairer les comportements humains. Ce faisant, les résultats obtenus concourent à rééquilibrer les connaissances acquises sur les pratiques de chasse aux rennes, accessibles dans la littérature depuis plusieurs années (Enloe, 1991, 1997, 2000b; Enloe, David, 1997; Bridault, Bemilli, 1999). Dès lors, nous aborderons et discuterons les modèles de l'organisation sociale des sociétés magdaléniennes et de leur évolution.

\section{HISTORIQUE DES REGHERCHES}

Le Magdalénien du Bassin parisien possède une notoriété qui a deux raisons principales. Tout d'abord, l'élaboration de fouilles planimétriques, d'abord appliquées à Pincevent, constitue un des apports méthodologiques majeurs d'A. Leroi-Gourhan et de l'équipe d'Ethnologie préhistorique (Leroi-Gourhan, Brézillon, 1972). Ensuite, la conservation de gisements multistratifiés exceptionnels comme Pincevent, Verberie, ou Étiolles ont favorisé une modélisation poussée des comportements techniques et sociaux préhistoriques (Leroi-Gourhan, Brézillon, ibid.; Audouze, 1987; Pigeot, 1987; Olive, 1988; Audouze et al., 1988; Julien et al., 1988, 1999; Bodu, 1993; Valentin, 1995; Olive et al., 2000; Valentin, Pigeot, 2000; Pigeot, 2004). Ces avancées pratiques et théoriques ont fait école, mais il faut remarquer que l'histoire des découvertes conditionne encore l'image des stratégies de subsistance des Magdaléniens dans le Bassin parisien.

À Pincevent comme à Verberie, les différents niveaux d'occupations dans lesquels le renne (Rangifer tarandus) représente plus de $90 \%$ des restes de faune, ont considérablement marqué les esprits (Leroi-Gourhan, Brézillon, 1972; Audouze et al., 1981). La qualité de la conservation de ces gisements (et des restes de faune) a permis une exploitation archéologique rarement atteinte par ailleurs (David in Leroi-Gourhan, Brézillon, ibid.; Enloe, David, 1989, 1997; Audouze, Enloe, 1991 ; Enloe, 1991, 1997; Enloe, Audouze, 1997). Il ressort que les rennes furent exploités sur ces sites lorsqu'ils formaient de larges troupeaux au cours de leurs migrations automnales. Les produits carnés étaient destinés à une consommation différée au cours de la saison hivernale et en prévision de la période de soudure. Cette représentation des Magdaléniens du Bassin parisien, qui fut en cohérence avec les données disponibles pendant de longues années, devra cependant être révisée à la lumière des découvertes régionales ayant eu lieu lors de la décennie 1990-2000.

Àquelques kilomètres de Pincevent, lors de travaux d'aménagements de l'autoroute A5, d'importantes occupations 
magdaléniennes furent découvertes au niveau de l'interfluve Seine-Yonne (Alix et al., 1993; Lang, 1998; Julien, Rieu dir., 1999). En dépit de contextes taphonomiques parfois médiocres, les sites du Grand Canton et du Tureau des Gardes ont montré que les Magdaléniens avaient chassé les chevaux de façon régulière, voire prépondérante (Bemilli, 1998; Bridault et al., 1997, 2003; Bridault, Bemilli, 1999). Les occupations magdaléniennes, très étendues dans l'interfluve de Marolles-sur-Seine, se seraient développées spatialement, au gré de recouvrements occasionnels opérés par la succession des séjours (Bridault et al., ibid.; Julien, Rieu dir., 1999). En dépit d'indices de saisonnalité probants, l'hypothèse de la chasse de ce gibier à l'année a été évoquée, prenant la forme d'une succession d'expédition de groupes de chasseurs magdaléniens (Bridault, 1997; Bridault et al., 1996, 1997; Julien, Rieu dir., 1999). Ces questionnements ont bousculé la vision d'une économie de subsistance magdalénienne fondée essentiellement sur la chasse aux rennes (Bridault et al., 1996, 1997; Julien, Rieu dir., 1999).

Toutefois, l'imprécision relative des datations et les fortes différences dans les spectres de faune ont donné lieu à des interprétations contrastées. Les plus anciennes traces de l'occupation magdalénienne dans le Bassin parisien remontent à environ $13000 \mathrm{BP}$, tandis que les plus récentes se situeraient vers 12000 BP (tabl. I; Audouze, 1992; Valentin, Pigeot, 2000). L'existence d'un plateau radiocarbone centré sur le Bölling (Magny, 1995) produit une distorsion susceptible à la fois de «vieillir » ou de « rajeunir » les datations ${ }^{14} \mathrm{C}$, sans qu'il soit possible de savoir dans quel sens! Les observations morpho-sédimentaires valident néanmoins l'occupation magdalénienne entre la fin du Dryas I et le Dryas II (Pastre et al., 2000). Cependant, il n'est pas possible d'avoir un ordonnancement chronologique fin des occupations sur la base des datations absolues, pas plus qu'en datation relative (d'après les critères technologiques actuels sur les armatures). Cette difficulté a généré deux modèles, opposés dans leur interprétation, des stratégies d'exploitation des ressources animales des Magdaléniens du Bassin parisien (Olive et al., 2000) :

- le modèle synchronique souligne la complémentarité fonctionnelle dans le cadre d'un cycle annuel entre les différents gisements; il présuppose une relative contemporanéité entre les sites ou certains niveaux et insiste sur la parenté culturelle claire (Julien, Rieu dir., 1999; Bridault et al., 2003 ; Bignon, 2003). Ainsi, les changements dans la composition du gibier sont interprétés comme le reflet d'objectifs variables en fonction des saisons et l'exploitation d'espèces animales variées et stables;
- le modèle diachronique explique la diversité des objectifs de chasse par l'évolution des systèmes d'exploitation dans le temps (Julien, Rieu dir., 1999; Enloe, 2000a, 2000b, 2000c). $\mathrm{Au}$ cours du Bölling, un bouleversement climatique et écologique brutal aurait amené les Magdaléniens du Bassin parisien à modifier globalement leur organisation sociale et certains aspects de leur système technique (organisation spatiale et adoption d'armatures axiales - les pointes à dos). Ces bouleversements culturels auraient également touché les objectifs cynégétiques: on serait passé d'une chasse préférentielle aux rennes, à celle des chevaux. En fait, les Magdaléniens auraient été contraints à suivre les changements écologiques, en tirant profit de l'augmentation de la biomasse du cheval et de la disparition du renne dans le Bassin parisien (Enloe, 2000a, 2000b, 2000c).

Dans la discussion, il sera temps de revenir sur les difficultés inhérentes à chacun de ces modèles. Auparavant, nous nous attacherons à rendre compte des modalités d'exploitation des chevaux, en termes d'activités techniques, de pratiques économiques et d'organisation sociale. Les questions ci-dessous formalisent le cadre de la problématique et seront traitées plus particulièrement dans cet article.

-Y a-t-il une ou plusieurs modalités d'exploitation des chevaux?

- Est-il possible d'identifier les tactiques de chasse?

- Dans quelles mesures les tactiques employées révèlentelles les stratégies de chasse et de subsistance?

- Qu'implique l'exploitation des chevaux faite par les Magdaléniens du Bassin parisien pour leur mode de vie?

\section{MÉTHODOLOGIE}

L'exploitation animale doit être envisagée comme le sous-système technique des matières premières animales d'un groupe humain ou d'une culture (Tresset, 1996; Vigne, 1998). Cette approche sera adoptée ici, sachant que les méthodes de l'archéozoologie tendent à mettre en évidence plus d'informations sur la phase d'acquisition des ressources par rapport au reste de la chaîne opératoire (Vigne, ibid.).

Les témoins osseux découverts dans les sites magdaléniens du Bassin parisien n'ont pas été systématiquement conservés. Seulement 12 sites ont pu livrer des données fauniques sur les 34 sites magdaléniens connus actuellement dans la région (fig. 1). La représentativité des résultats archéozoologiques pourrait être mise en doute si plusieurs sites majeurs (Pincevent, Verberie, les sites de Marolles-sur- 


\begin{tabular}{|c|c|c|c|c|}
\hline $\begin{array}{l}\text { Site du Bassin } \\
\text { parisien }\end{array}$ & $\begin{array}{l}\text { Référence } \\
\text { laboratoire }\end{array}$ & $\begin{array}{l}\text { Datations BP } \\
\text { (2 sigmas) }\end{array}$ & $\begin{array}{l}\text { Datations } \\
\text { Cal BP }\end{array}$ & Matériel \\
\hline \multicolumn{5}{|l|}{$\begin{array}{l}\text { Étiolles } \\
\text { (Étiolles, Essonne) }\end{array}$} \\
\hline $\mathrm{Q} / \mathrm{R} 5$ & Ly 1351 & $12000 \pm 220$ & $14450-13450$ & \\
\hline $\mathrm{N} 20$ & Oxa 138 & $12990 \pm 300$ & $16450-14250$ & \\
\hline $\mathrm{N} 20$ & Oxa 139 & $13000 \pm 300$ & $16450-14250$ & \\
\hline N20 & Oxa 173 & $12800 \pm 220$ & $16050-14250$ & \\
\hline N20 & Oxa 175 & $12900 \pm 220$ & $16150-14250$ & \\
\hline \multicolumn{5}{|l|}{$\begin{array}{l}\text { Marsangy } \\
\text { (Marsangy, Seine-et-Marne) }\end{array}$} \\
\hline Unité N19 & Oxa 178 & $11600 \pm 200$ & $14150-12950$ & Rangifer \\
\hline Unité D14 & Oxa 740 & $12120 \pm 180$ & $15450-13550$ & Rangifer \\
\hline \multicolumn{5}{|c|}{$\begin{array}{l}\text { Le Grand Canton } \\
\text { (Marolles-sur-Seine, Seine-et-Marne) }\end{array}$} \\
\hline Secteur $2 /$ secteur 18 & Gif 9608 & $12880 \pm 80$ & $15950-14350$ & Rangifer \\
\hline Secteur 2/secteur 18 & Gif 9606 & $12195 \pm 130$ & $15450-13750$ & Equus \\
\hline Secteur 2/secteur 18 & Gif 9607 & $12080 \pm 115$ & $15450-13650$ & Equus \\
\hline Secteur 2/secteur 18 & Gif 9609 & $11420 \pm 100$ & $13850-13000$ & Equus \\
\hline Secteur 1 & Oxa 3671 & $11030 \pm 105$ & $13400-12650$ & Equus \\
\hline Secteur 1 & Oxa 3139 & $12650 \pm 130$ & $15750-14250$ & Equus \\
\hline \multicolumn{5}{|c|}{\begin{tabular}{|l|} 
Tureau des Gardes \\
(Marolles-sur-Seine, Seine-et-Marne) \\
\end{tabular}} \\
\hline TDG Secteur 1 & Ly 6988 & $12290 \pm 90$ & $15450-14050$ & Os \\
\hline TDG Secteur 10 & AA 44214 & $12170 \pm 130$ & $15450-13650$ & Equus \\
\hline TDG Secteur 10 & AA 44215 & $12160 \pm 120$ & $15450-13650$ & Equus \\
\hline TDG Secteur 10 & AA 44216 & $12520 \pm 130$ & $15550-14150$ & Equus \\
\hline \multicolumn{5}{|l|}{$\begin{array}{l}\text { Ville-Saint-Jacques, Le Tilloy } \\
\text { (Seine-et-Marne) }\end{array}$} \\
\hline Sondage 1970 & Oxa 730 & $12300 \pm 160$ & $15450-13750$ & Os \\
\hline Sondage 1970 & Oxa 731 & $12240 \pm 160$ & $15450-13750$ & Os \\
\hline \multicolumn{5}{|c|}{\begin{tabular}{|l|} 
Pincevent \\
(La Grande Paroisse, Seine-et-Marne) \\
\end{tabular}} \\
\hline Niveau IV-Habitation 1 & Gif 358 & $12300 \pm 40$ & $15450-14050$ & Charbon \\
\hline Niveau IV40 & Gif 5971 & $12100 \pm 120$ & $15350-13650$ & Charbon \\
\hline Niveau IV30 & Gif 6310 & $12100 \pm 130$ & $15350-13650$ & Charbon \\
\hline Niveau IV213 & Gif 6284 & $11800 \pm 130$ & $14350-13350$ & Charbon \\
\hline Niveau IV213 & Oxa 149 & $12400 \pm 200$ & $15550-13650$ & Os \\
\hline Niveau IV213 & Oxa 176 & $12000 \pm 220$ & $15350-13450$ & Os \\
\hline Niveau IV213 & Oxa 177 & $12300 \pm 220$ & $15550-13750$ & Os \\
\hline Niveau IV20 & Oxa 148 & $12600 \pm 200$ & $15750-14050$ & Os \\
\hline Niveau IV20 & Gif 6283 & $12120 \pm 130$ & $15450-13650$ & Charbon \\
\hline Niveau IV20 & Oxa 467 & $12250 \pm 160$ & $15450-13750$ & Charbon \\
\hline \multicolumn{5}{|l|}{$\begin{array}{l}\text { Verberie, Le Buisson Campin } \\
\text { (Oise) }\end{array}$} \\
\hline Niveau II.1 & Gif A95453 & $12430 \pm 120$ & $13495-12174$ & Os \\
\hline Niveau II.2 & Gif A95454 & $12950 \pm 130$ & $14107-12517$ & Os \\
\hline Niveau II.3 & Gif A99106 & $12520 \pm 120$ & $13549-12213$ & Os \\
\hline Niveau II.4 & Gif A99421 & $12300 \pm 120$ & $13471-11905$ & Os \\
\hline
\end{tabular}

Tabl. I - Datations radiocarbone obtenues pour les sites magdaléniens du Bassin parisien (Bignon, 2003). Calibration obtenue avec Oxcal 3.5 (http://c14.arch.ox.uk/oxcal. php). 


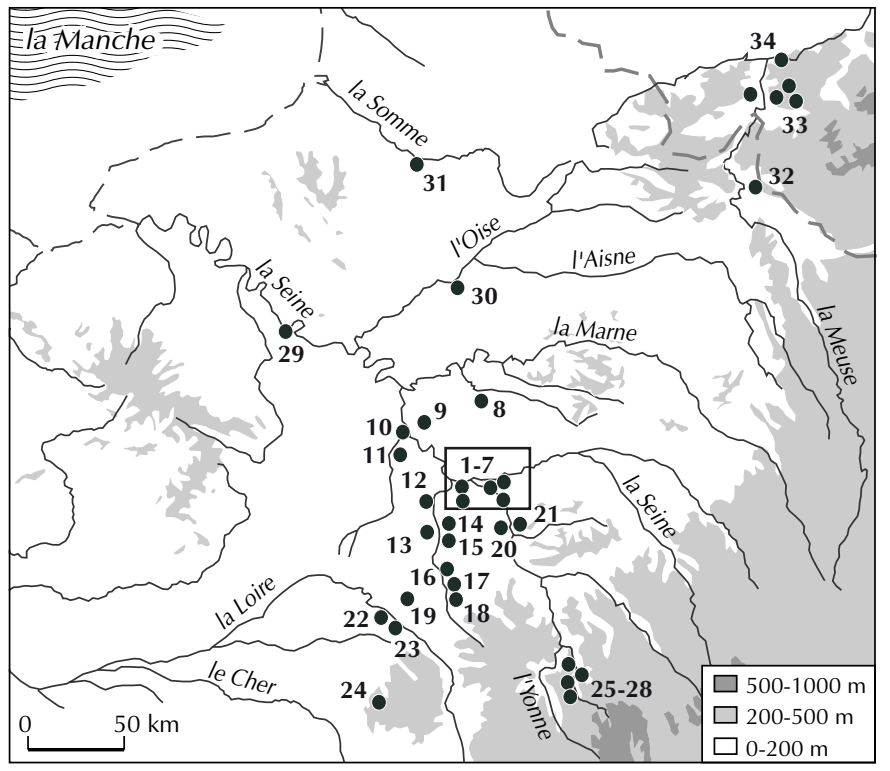

Fig. 1 - Carte des sites magdaléniens du Bassin parisien (d'après Julien, Rieu dir., 1999).

1, Pincevent à La Grande-Paroisse; 2, Le Tilloy à Ville-SaintJacques; 3, Le Marais du Pont à Varennes-sur-Seine; 4, Le Grand Canton à Marolles-sur-Seine; 5, Le Tureau des Gardes à Marollessur-Seine; 6, Le Chemin de Sens à Marolles-sur-Seine;

7, Le Chemin de Montereau à Barbey; 8, Lumigny; 9, Les Coudrays à Étiolles; 10, Les Tarterêts à Corbeil-Essonnes; 11, Ballancourtsur-Essonne; 12, La Vignette à Villiers-sous-Grez; 13, Le Rocher à Chaintréauville (Saint-Pierre-de-Nemours); 14, Les Gros Monts à Nemours; Le Beauregard à Nemours; 16, La Maison Blanche à Fontenay-sur-Loing; 17, La Pierre aux Fées à Cepoy; 18, Châlettesur-Loing; 19, La Jouanne aux Choux; 20, Le Pré des Forges à Marsangy; 21, Villeneuve-sur-Yonne; 22, Les Couches Bæufs à Poilly-lez-Gien; 23, Mancy à Saint-Brisson-sur-Loire; 24, Le Laitier Pilé à Saint-Palais; 25, Le Lagopède à Arcy-sur-Cure;

26, Le Trilobite à Arcy-sur-Cure; 27, Les Fées à Arcy-sur-Cure; 28, La Marmotte à Saint-Moré; 29, La Côte Masset à Bonnièressur-Seine; 30; Le Buisson Campin à Verberie; 31, Belloy-surSomme; 32, Roc-la-Tour; 33, Chaleux (Belgique); 34, Goyet (Belgique).

Seine) n'avaient pas contenu des milliers de témoins (dans plusieurs niveaux ou secteurs), atténuant un constat a priori pessimiste (tabl. II).

En relation avec les contextes taphonomiques, les modalités d'exploitation d'une ressource animale sont généralement mises en lumière par (Enloe, 1997; Costamagno, 1999):

- la recherche du Nombre minimum d'individu de comparaison (NMIc) ;
Tabl. II - Nombre d'espèces animales et nombre de restes déterminés (NRd) des sites magdaléniens du Bassin parisien (d'après Enloe, 1997; Poplin, 1992; Schmider et al., 1995; Bignon, 2003, 2004; Bignon et al., 2006, ce volume).

\begin{tabular}{|l|c|c|}
\hline \multicolumn{1}{|c|}{ Sites } & $\begin{array}{c}\text { Nombre } \\
\text { d'espèces animales }\end{array}$ & $\begin{array}{c}\text { Nombre de restes } \\
\text { déterminés (NRd) }\end{array}$ \\
\hline Étiolles, «Amas de cheval» & 4 & 280 \\
\hline Le Grand Canton, secteur 2 & 5 & 5467 \\
\hline Tureau des Gardes 5-6 & 5 & 2904 \\
\hline Tureau des Gardes 10 & 5 & 4693 \\
\hline Pincevent IV20, secteurs 27 et 36 & 7 & 1318 \\
\hline Pincevent IV0 & 5 & 548 \\
\hline Ville-Saint-Jacques & 4 & 835 \\
\hline Verberie, niveau II.1 & 4 & $?$ \\
\hline Le Lagopède, niveaux C1, C2, C3 & 7 & 122 \\
\hline Marsangy & 3 & 36 \\
\hline Bonnières-sur-Seine & 3 & 14 \\
\hline Trou de la Marmotte & 5 & 43 \\
\hline
\end{tabular}

- l'établissement d'un profil paléodémographique;

- la prise en compte des estimations de saisonnalité des animaux abattus;

- la représentation différentielle des parties anatomiques.

Les apports de ce travail renvoient notamment à un réexamen des NMIc et des profils paléo-démographiques des principaux sites concernant le cheval, ainsi que l'établissement d'une méthode originale pour déterminer leur saison d'abattage (Bignon, 2003 et à paraître). En outre, les notions de tactiques et stratégies de chasse nécessitent dès à présent d'être définies dans la mesure où on a pu leur donner des sens variables dans la littérature archéologique. Ainsi, nous entendons par tactique de chasse, l'ensemble des dispositifs techniques (armes et installations selon la terminologie d'Oswalt, 1976), le type de chasse (individuelle/ collective) et les contextes de la conduite d'une activité de chasse (saison, caractéristique topo-géographique, etc.). Par stratégie de chasse, il est fait référence à la capacité d'un groupe social à fixer et à organiser des objectifs cynégétiques sur un taxon donné, au cours d'un ou plusieurs cycles annuels. Les stratégies de chasse d'un groupe humain renvoient donc à l'ensemble des ressources exploitées et leurs modalités (espèces, nombre d'espèces, proportions relatives entre les proies, variables de classe d'âge ou de groupes sociaux, saisons, lieux, etc.), et s'inscrivent à ce titre dans les stratégies de subsistance (Fontana, 1998). 


\section{MODÈLES PALÉODÉMOGRAPHIQUES ET EXPLOITATION DES CHEVAUX}

Toutes les hypothèses ont été testées pour envisager l'exploitation des chevaux magdaléniens du Bassin parisien, dont celles avancées par P. G. Bahn (1980, 1984a, 1984b, 1989, 1990), relatives au contrôle des troupeaux de grands mammifères par les chasseurs-cueilleurs du Paléolithique supérieur. De nombreuses séries d'incisives font l'objet d'un examen attentif sur la plupart des sites magdaléniens du Bassin parisien (Bignon, 2003). Effectivement, sur ces dernières il est possible d'identifier une usure anormale correspondant à un stress lié à l'immobilité forcée chez les équidés (Bahn, 1980). Les hypothèses de cet auteur sont pour le moins controversées, mais il est intéressant de vérifier l'idée d'une capture dans l'optique d'une pratique d'apprivoisement ou de l'usage d'un leurre animal pour une chasse à l'appelant, ou bien encore pour le bât et la monte. L'absence de traces de ticage ne permet pas de valider ces éventualités en l'état actuel des recherches (Bignon, 2003). Si la capture des équidés fut réalisée par les Magdaléniens, cette pratique fut suffisamment marginale pour ne pas être décelable dans les assemblages fauniques étudiés.

Dans le cadre géographique du Bassin parisien, la chasse doit ainsi être considérée comme le moyen essentiel employé au Magdalénien pour se procurer des chevaux. Pour reconstituer les pratiques de chasse potentiellement choisies, nous nous sommes inspirés des modèles cynégétiques élaborées par M. A. Levine (1979, 1983). Certaines modifications y ont été apportées, au gré d'une confrontation critique d'après la littérature existante sur les chasseurs d'équidé des périodes historiques et préhistoriques. Dans cette reformulation, différentes modalités cynégétiques peuvent être perçues en regard du nombre de gibier abattu, des profils paléodémographiques et des caractéristiques du traitement boucher et de la consommation. Ces modèles cynégétiques sont présentés ci-dessous.

- La chasse de poursuite: elle se décline potentiellement en deux options, l'une à pied et l'autre avec monture (chevaux apprivoisés), mais le but est d'anticiper le déplacement de la proie. À pied, l'endurance de l'équidé est éprouvée pendant une ou plusieurs journées par un homme seul ou par un petit groupe d'individus. Avec monture, un petit groupe d'hommes peut aller directement à la rencontre des bandes et provoquer la poursuite. Dans ce type de chasse, les juvéniles (jusqu'à 2 ans) et les animaux les plus âgés ou malades sont les proies les plus vulnérables, donnant lieu à un profil de mortalité de type attritionnel. Toutefois, intervenant plusieurs millénaires avant la domestication du cheval et en l'absence de preuves d'apprivoisement, la chasse de poursuite avec monture n'est pas envisageable au Magdalénien dans le Bassin parisien.

- La chasse d'approche: pratiquée par un chasseur ou un petit nombre d'hommes, cette chasse vise à s'approcher le plus possible des proies en utilisant des leurres pour masquer son apparence humaine (peaux d'autres animaux). L'abattage d'équidés est facilité par les armes de chasse réduisant la distance avec le gibier (lances, arc et flèches, sagaies et propulseurs). Cette tactique touche plus particulièrement les juvéniles (entre 10 et 15 ans ; moins aguerris à la prédation), les vieux adultes (moins vifs, plus isolés pour les mâles solitaires) et les individus malades ou blessés. Là encore, on aboutit à un profil de mortalité de type attritionnel.

- La chasse à l'appelant: utilisation de spécimens captifs pour attirer un ou plusieurs congénères. Lorsque ceux-ci sont suffisamment proches, les chasseurs usent de leurs projectiles pour tuer ou blesser les animaux curieux. Cette tactique fut utilisée aux $\mathrm{XVII}^{\mathrm{e}}$ et XVIII ${ }^{\mathrm{e}}$ siècles par les Indiens Kiowa (dans le sud-est des Grandes Plaines aux États-Unis), pour attirer les groupes de chevaux célibataires (Bignon, 2006). Le profil d'abattage qui résulte de l'emploi de cette tactique aboutit à un profil de mortalité centré sur les subadultes (de 2 à 5 ans) et les jeunes adultes (entre 5 et 10 ans ; Levine, 1983, 2003).

- La chasse d'interception: elle correspond à l'abattage de plusieurs individus par l'action concertée de plusieurs chasseurs à l'affût, préalablement disposés en un lieu favorable de la piste empruntée quotidiennement ou saisonnièrement par le gibier. Le profil de mortalité associé à cette chasse tend à s'approcher de la courbe de survie d'une population vivante ou d'un profil de mortalité de type catastrophique.

- La chasse par piégeage: l'aménagement d'une fosse de profondeur variable (avec ou sans piques) au niveau des points d'eau ou sur les routes de migrations principales. Cette tactique vise à abattre un grand nombre d'individus lors de la même opération et de ce fait concerne les bandes ayant une démographie importante, les groupes familiaux. Également, dans le sens où elle conditionne l'accès aux autres points d'eau dans les environs immédiats, on peut admettre qu'elle est une variante des chasses de rabattage. Le profil d'abattage tend à s'approcher du profil démographique d'une population vivante ou du profil d'abattage de type catastrophique.

- La chasse de rabattage de bandes: cette tactique collective a pour objectif de capter un grand nombre de gibiers. Le but 
est de contraindre les animaux à fuir groupés en direction d'un second groupe humain prêt à abattre un maximum de proies. L'utilisation de la course (avec ou sans chiens), de l'approche ou de montures sont attestées, de même que des contextes topographiques avantageux (canyons, marécages, etc.) associés ou non à des dispositifs techniques (palissades, système à barrières convergentes, à enclos). Ici également, le profil d'abattage s'apparente à celui d'une population vivante ou d'un profil de mortalité de type catastrophique.

\section{TAPHONOMIE ET TYPES DE SPECTRES}

Les contextes taphonomiques des différents sites magdaléniens du Bassin parisien présentent des différences parfois importantes, notamment en termes d'intégrité des surfaces osseuses (altérations préalables à l'enfouissement, traces de radicelles), de fracturation (sur os frais ou sec) et d'altération aux agents physico-chimique (fig. 2). En revanche, tous les sites ont en commun d'avoir révélé de faibles pourcentages de traces de carnivores et d'être incompatibles avec les modèles d'accumulation ou de dispersion artificielles de parties squelettiques, liés aux transports fluviaux (Voorhies, 1969; Bignon, 2003).

Sur les sites du Tureau des Gardes et du Grand Canton, une fonte taphonomique significative s'est produite dans certains secteurs ou dans certaines zones à l'intérieur de secteurs (Bemilli, 1998; Bridault, Bemilli, 1999). Toutefois, la conservation différentielle de ces gisements n'est pas une cause suffisante pour expliquer la sous-représentation des autres grands herbivores comme le renne, les bovidés ou le mammouth dans la plupart des secteurs (Bridault et al., 1996, 2003; Bemilli, 1998; Bridault, Bemilli, 1999). À Étiolles, si un bilan taphonomique doit encore préciser ces questions (Bignon, en préparation), une fonte taphonomique importante est déjà vraisemblable (Poplin, 1994), avec cependant une forte variabilité spatiale ou entre les niveaux archéologiques. Il faut remarquer qu'un site comme Pincevent connaît également une certaine variabilité des contextes taphonomiques entre ses divers niveaux magdaléniens, moins favorables pour le niveau IV0 (Bignon et al., 2006 [ce volume]). Ces phénomènes ne semblent pas avoir lieu à Verberie dont les différents niveaux offrent une grande homogénéité (Enloe, 1997).

L'analyse des spectres fauniques révèle que les pratiques cynégétiques magdaléniennes comportent des espèces récurrentes, régulières ou ponctuelles (tabl. III). Au total, 16 taxons ont pu être identifiés (sans compter les oiseaux),

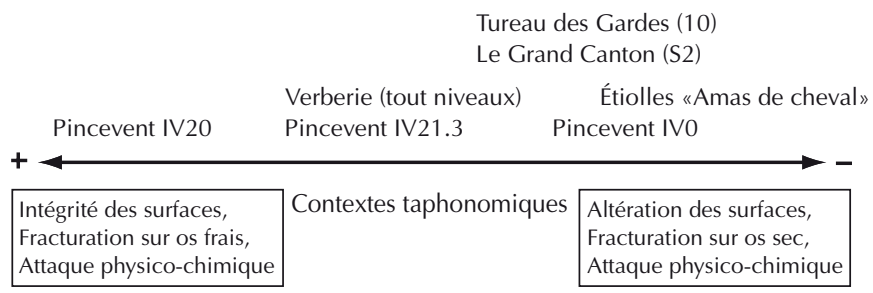

Fig. 2 - Représentation schématique de la variabilité des contextes taphonomiques des sites magdaléniens du Bassin parisien étudiés.

Tabl. III - Liste des espèces animales des sites magdaléniens du Bassin parisien (d'après Bignon, 2003).

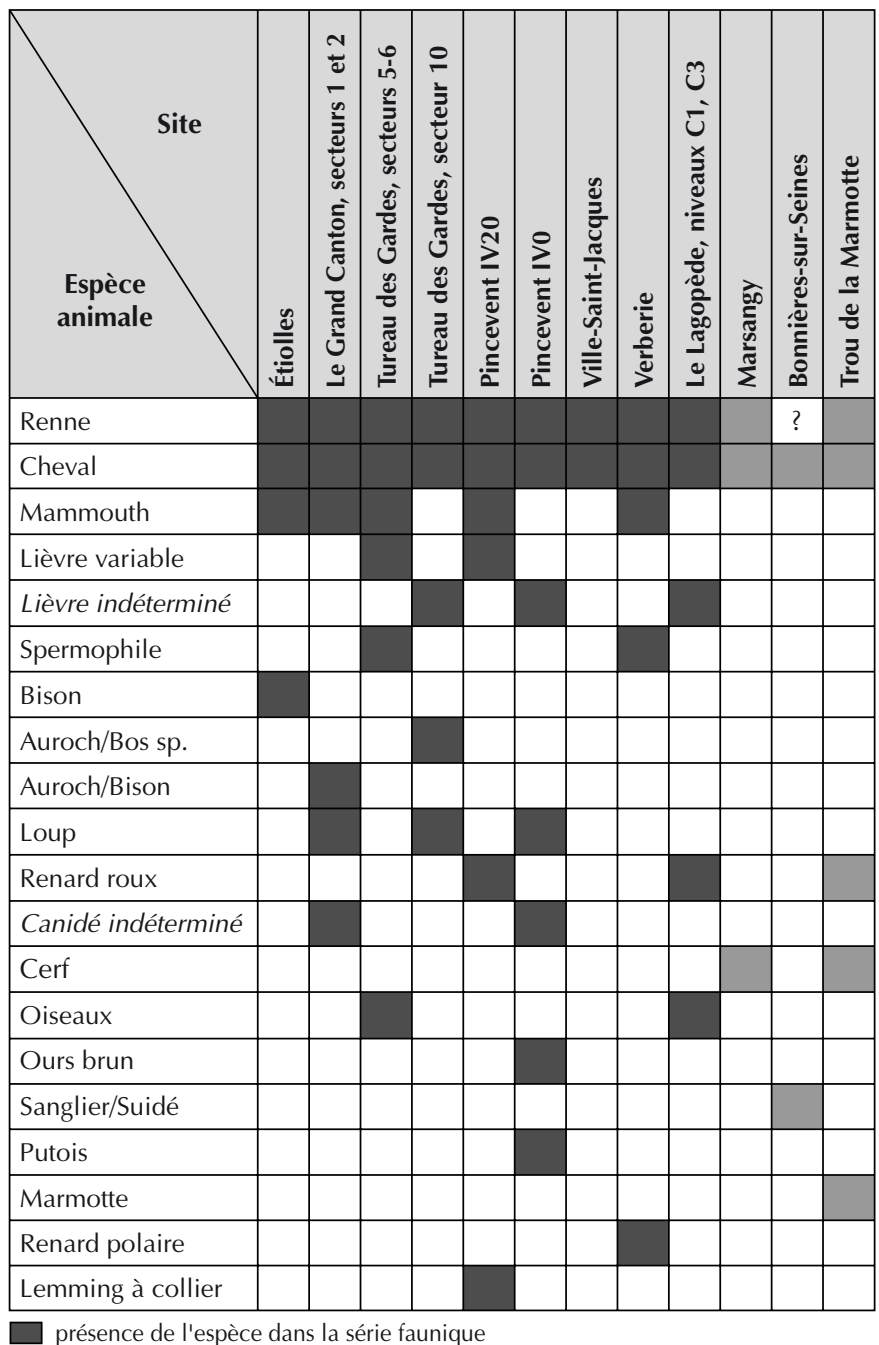

présence de l'espèce dans la série faunique

présence de l'espèce dans une série faunique ayant moins de 60 restes déterminés

dont 5 carnivores. Néanmoins, si la diversité spécifique des spectres fauniques peut apparaître plutôt restreinte à l'échelle des sites, elle est relativement plus étendue à l'échelle régionale. Par comparaison, cette diversité est 


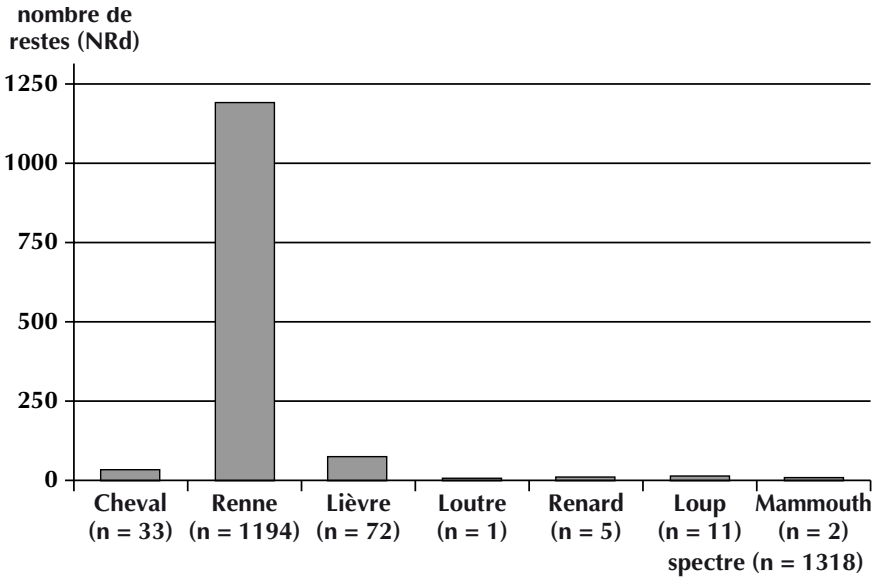

a. Pincevent IV20

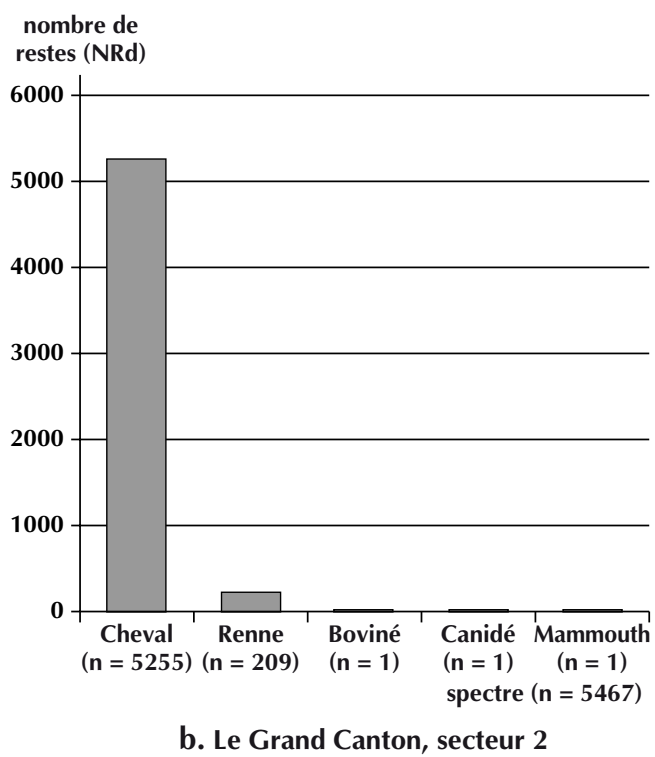

Fig. 3 - Sites magdaléniens à domination quasi exclusive (nombre de restes déterminés): a, domination du renne, Pincevent IV2O (d'après Enloe, 1991); b, domination du cheval, Le Grand Canton, secteur 2 (d'après Bridault, Bemilli, 1999).

légèrement moins importante dans le Bassin parisien par rapport à ce qu'il a pu être dénombré en Allemagne (15 mammifères et 6 carnivores; Gaudzinski, Street, 2003) ou en Belgique (15 mammifères et 11 carnivores; Charles, 1998).

Les deux animaux systématiquement retrouvés dans tous les sites du Bassin parisien sont les rennes et les chevaux. Ces animaux occupent de surcroît une place prépondérante en termes de richesse des spectres fauniques et génèrent de forts contrastes entre les sites. En définitive, trois types

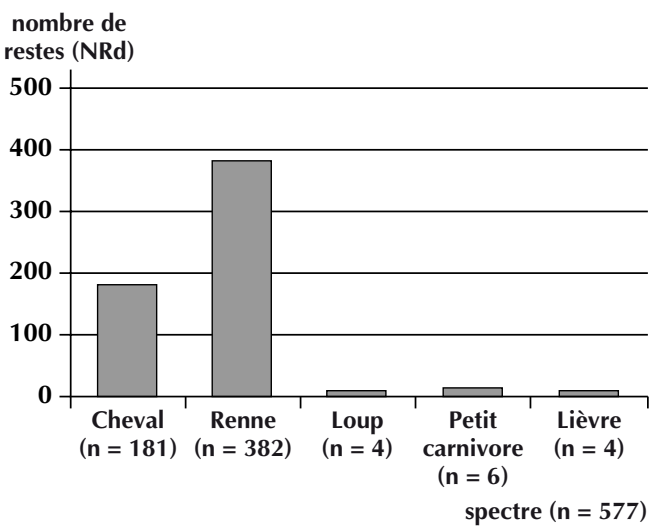

a. Pincevent IV0

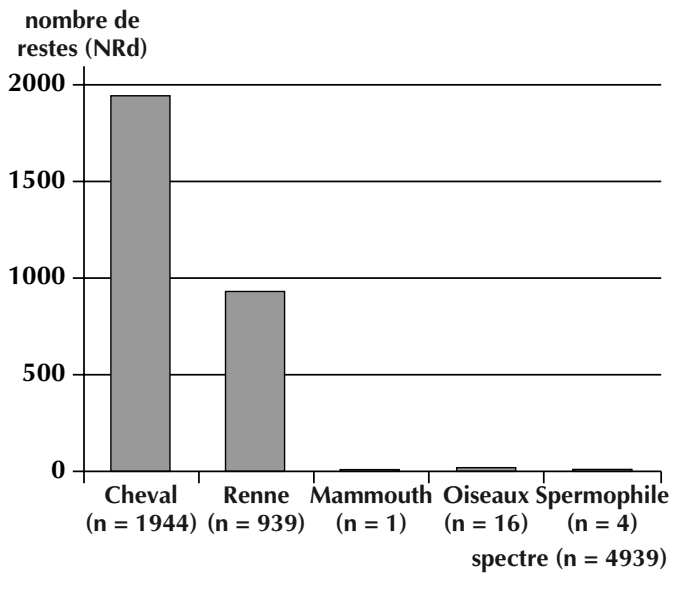

b. Tureau des Gardes 5-6

Fig. 4 - Sites magdaléniens dominés conjointement par les rennes et les chevaux (nombre de restes déterminés): a, Pincevent IVO (d'après Bignon et al., à paraître); b, Le Tureau des Gardes, secteur 5-6 (d'après Bemilli, 1998).

de richesse caractérisent les spectres de faune du Bassin parisien au Magdalénien (tabl. IV; Bignon, 2003) :

- les sites quasi exclusivement dominés par le renne ou le cheval (au moins $85 \%$ du NR; fig. 3) : par exemple, le renne domine les spectres des différents niveaux de Verberie et de nombreux niveaux de Pincevent (IV20, IV30, IV40, Habitation $n^{\circ} 1$ ); le cheval est largement prédominant dans le secteur $2 \mathrm{du}$ Grand Canton et les secteurs 7, 8, 9, $10 \mathrm{du}$ Tureau des Gardes;

- les sites dominés conjointement par le cheval et le renne (fig. 4) : c'est le cas dans le secteur 5-6 du Tureau des Gardes, le niveau IV0 de Pincevent, ou les sites de Marsangy, les occupations d'Étiolles, Bonnières-sur-Seine, Villes-SaintJacques (Bignon, 2004, sous presse); 


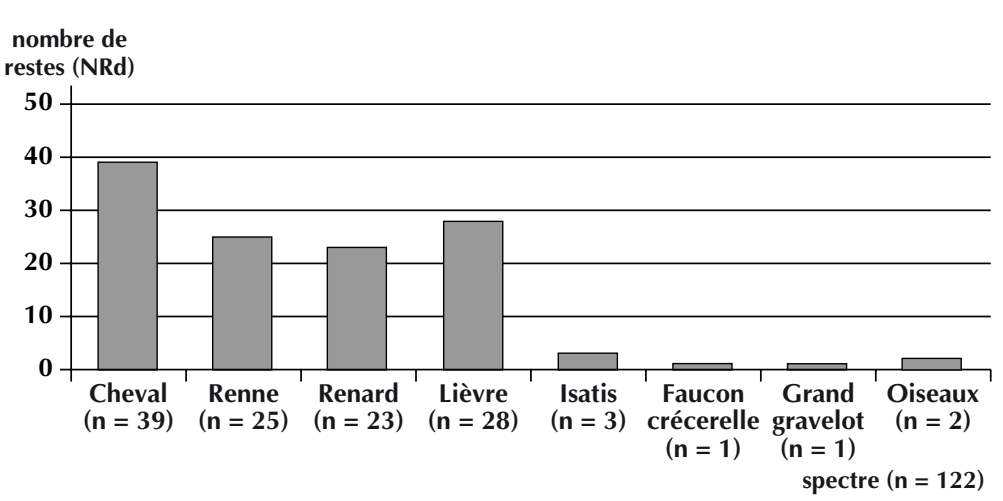

a. Le Lagopède

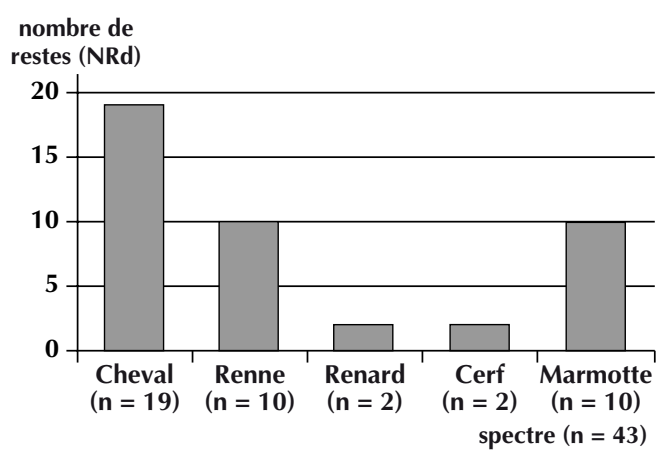

b. Le Trou de la Marmotte

Fig. 5 - Sites magdaléniens à représentation spécifique équilibrée (nombre de restes déterminés): a, abri du Lagopède C (d'après Schmider et al., 1995); b, Le Trou de la Marmotte (d'après Schmider et al., 1995).

- les sites ayant une représentation équilibrée entre plusieurs taxons (fig. 5) : il s'agit essentiellement des petites occupations de la vallée de la Cure (Yonne), comme l'abri du Lagopède à Arcy-sur-Cure et le Trou de la Marmotte à Saint-Moré.

\section{L'EXPLOITATION DES CHEVAUX}

S'il n'est pas possible d'exposer ici la totalité des résultats, nous avons choisi d'illustrer l'exploitation des chevaux au Magdalénien par quelques exemples caractéristiques. De ces travaux, une vision d'ensemble émerge et met en lumière les modalités d'acquisition et de traitement de ces grands gibiers.

\section{L'« AMAS DE CHEVAL » D’ÉTIOLLES}

Le peu de faune découverte dans les occupations d'Étiolles (Pigeot, 1987; Olive, 1988; Coudret et al., 1994), renvoie vraisemblablement à une conservation différentielle entre les niveaux archéologiques, voire à l'intérieur d'un même sol d'occupation (Bignon, 2003). Les observations taphonomiques de F. Poplin (1994) suggèrent en effet que la faune découverte n'est qu'une infime partie des restes squelettiques laissés par les Magdaléniens. Ainsi, l'«amas de cheval ", du fait de la grande concentration de vestiges, pourrait avoir mieux résisté à la fonte taphonomique.

L'analyse des séries dentaires indique que trois chevaux ont constitué cette concentration faunique, confirmant les observations de F. Poplin (1994). Un juvénile d'à peine plus de 1 an a pu être déterminé d'après l'usure de ses dents déciduales. Le second équidé est un subadulte d'environ
4 ans, tandis que le troisième est un adulte dont l'âge peut être estimé entre 9 et 10 ans. La présence d'un juvénile indique que les chasseurs magdaléniens se sont attaqués à un groupe familial, car les poulains sont indissociables de leur génitrice jusqu'à l'âge de 2 ans environ (Berger, 1986; Duncan, 1992; Bignon, 2003). Étant donné le traitement groupé de ces individus, en ce seul endroit dans le gisement, il est raisonnable de penser qu'ils ont été abattus lors du même épisode de chasse. Dans cette optique, l'âge des deux autres individus a pu correspondre à une jument pour le subadulte et à un étalon comme l'a suggéré F. Poplin (1994). Cette hypothèse est effectivement la plus plausible en raison des canines bien développées par l'adulte et du fait que les subadultes des groupes familiaux sont essentiellement composés de juments. L'abattage de plusieurs individus lors d'un unique épisode de chasse plaide pour l'adoption d'une tactique de type interception ou rabattage de bande, nécessitant une organisation collective des chasseurs.

Les mesures des dents jugales déciduales (supérieures et inférieures) du poulain indiquent un âge moyen de 12,99 mois ( \pm 1 mois; Bignon, 2003). Ces données semblent être confirmées par l'usure des incisives et l'éruption récente des premières molaires. La chasse s'est donc déroulée au printemps.

La forte concentration d'ossements de chevaux (fig. 6), à l'origine du terme "amas ", exprime l'aspect massif $\mathrm{du}$ dépotoir osseux après traitement des carcasses. Les animaux ont pu être ramenés entiers, mais la conservation délicate des ossements ne permet pas de dire si les parties du rachis (côtes et vertèbres) furent abandonnées sur le lieu d'abattage, apportées à Étiolles, transportées ailleurs ou simplement détruites. En revanche, la représentation des 


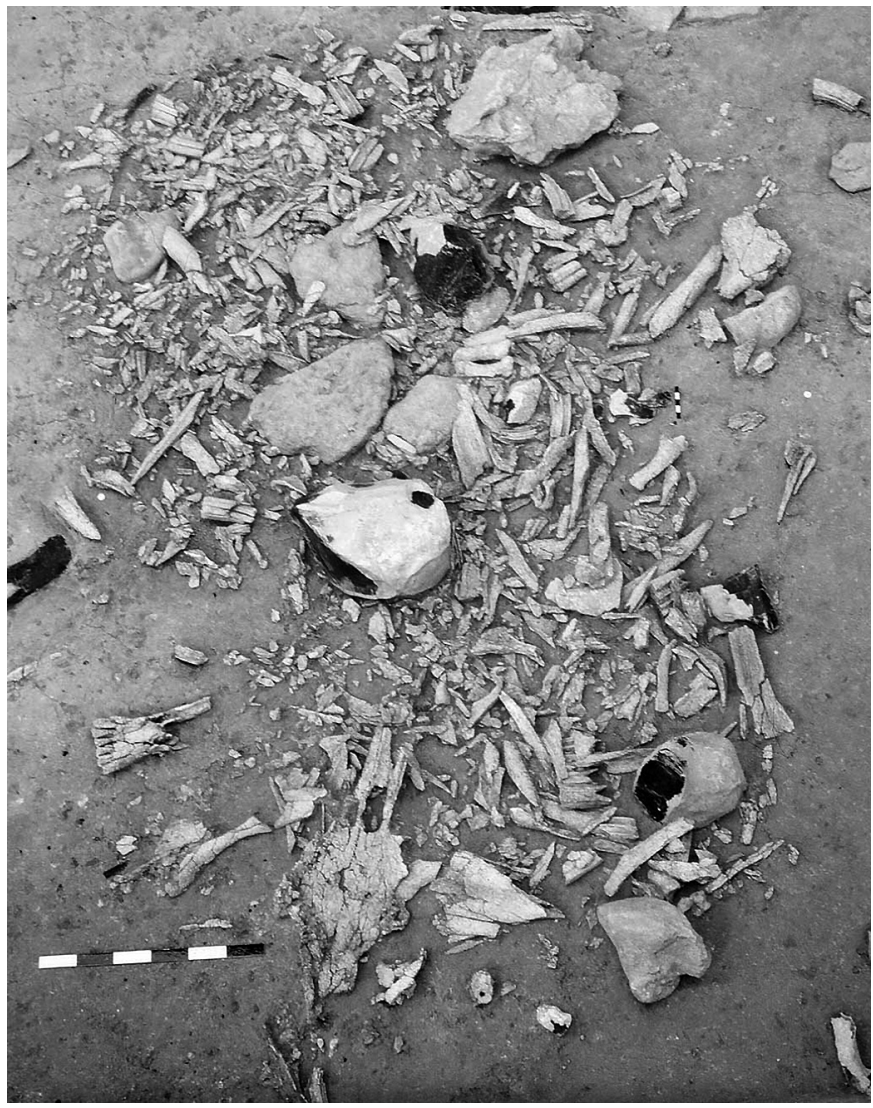

Fig. 6 - Photographie de l'« amas de cheval » d'Étiolles (photo Centre d'Étiolles).

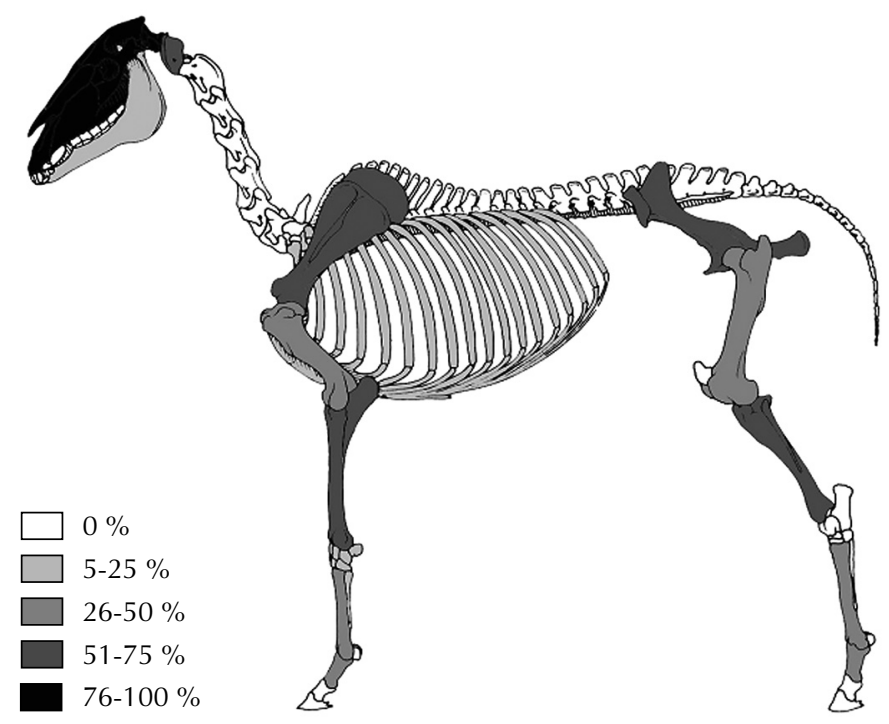

Fig. 7 - Représentation des parties squelettiques des chevaux (\% parties observées) de l'« amas » d'Étiolles. parties squelettiques atteste la présence dans « l'amas » de segments transportables, comme la tête ou les membres et leurs ceintures thoraciques et pelviennes respectives (fig. 7). Une consommation in situ est vraisemblable du fait que les os longs sont systématiquement fracturés pour récupérer la moelle, opération forcément précédée par une décarnisation des carcasses. L'estimation de la valeur nutritive des trois chevaux, en s'en tenant uniquement aux membres et aux parties crâniales, peut être évaluée à environ $215 \mathrm{~kg}$ de viande et de moelle.

L'« amas de cheval » d'Étiolles est un exemple unique dans le Bassin parisien de la chasse et du traitement d'un groupe harem par les Magdaléniens. En cela, il peut avoir valeur de modèle pour les sites plus complexes et plus denses de Marolles-sur-Seine (Seine-et-Marne).

\section{PINCEVENT IVO}

Le contexte taphonomique du niveau IV0 de Pincevent peut être considéré comme médiocre dans l'unité T125, car les témoins osseux sont généralement altérés par weathering et portent d'importantes traces de radicelles (Bignon et al., 2006 [ce volume]), Si une fonte taphonomique est vraisemblable, le facteur humain a aussi joué un rôle de par la fracturation systématique des os longs et peut-être dans la représentation différentielle des parties squelettiques.

Pour l'unité T125, contenant l'essentiel des vestiges du IV0, le spectre faunique renvoie à une domination conjointe des chevaux $(n=9)$ et des rennes $(n=10)$, soit respectivement $40,9 \%$ et $45,45 \%$ du NMIc (tabl. IV). Les séries dentaires identifiées montrent une forte représentation des juvéniles et des subadultes, la classe des adultes étant faiblement attestée et celle des vieux adultes absente (fig. 8). Le profil de mortalité obtenu montre que les Magdaléniens ont visé essentiellement des harems, car seuls ces groupes sociaux intègrent des juvéniles et la plupart des subadultes (Levine, 1979, 1983; Bignon, 2003). La faune de l'occupation du IV0 correspond à au moins trois épisodes de chasse (Bignon et al., 2006 [ce volume]) : 4 subadultes ont été abattus en automne; 2 juvéniles au cours de la période hivernale; enfin, un poulain de 2 ans indique une mort intervenant au début du printemps. Si une tactique collective (interception/rabattage) a pu être employée à l'automne pour atteindre les subadultes, il apparaît que des chasses plus individuelles (approche/affût) aient pu être mises en ouvre pour les autres saisons. Ceci n'a rien d'étonnant pour la période hivernale si l'on considère que l'espacement inter-individuel et inter-bande des chevaux à 


\begin{tabular}{|c|c|c|}
\hline Sites & Espèces animales & $\begin{array}{c}\text { Nombre minimum d'individus } \\
\text { de combinaison (NMIc) }\end{array}$ \\
\hline \begin{tabular}{|l} 
Étiolles, \\
«Amas de cheval»
\end{tabular} & $\begin{array}{l}\text { 1, cheval } \\
\text { 2, renne } \\
3, \text { bison } \\
4, \text { mammouth } \\
\end{array}$ & $\begin{array}{l}3 \\
1 \\
1 \\
1\end{array}$ \\
\hline $\begin{array}{l}\text { Le Grand Canton, } \\
\text { secteur } 2^{*}\end{array}$ & $\begin{array}{l}\text { 1, cheval } \\
\text { 2, renne } \\
3, \text { boviné } \\
\text { 4, mammouth } \\
\text { 5, canidé }\end{array}$ & $\begin{array}{c}117 \\
14 \\
1 \\
1 \\
1 \\
\end{array}$ \\
\hline Tureau des Gardes 5-6 & \begin{tabular}{|l|} 
1, cheval \\
2, renne \\
3, oiseaux \\
4, lièvre/lagopède \\
5 , mammouth \\
\end{tabular} & non disponible \\
\hline Tureau des Gardes 10 & $\begin{array}{l}\text { 1, cheval } \\
\text { 2, renne } \\
\text { 3, boviné } \\
\text { 4, lagopède } \\
\text { 5, loup } \\
\end{array}$ & $\begin{array}{c}89 \\
18^{*} \\
1 \\
1 \\
1 \\
\end{array}$ \\
\hline Pincevent IV20 & $\begin{array}{l}\text { 1, renne } \\
\text { 2, lièvre } \\
\text { 3, renard } \\
4 \text {, cheval } \\
\text { 5, loup } \\
6 \text {, loutre } \\
\text { 7, mammouth }\end{array}$ & $\begin{array}{c}77 \\
4 \\
2 \\
1 \\
1 \\
1 \\
1\end{array}$ \\
\hline Pincevent IV0 & $\begin{array}{l}\text { 1, renne } \\
\text { 2, cheval } \\
3 \text {, lièvre } \\
\text { 4, loup } \\
\text { 5, petit carnivore }\end{array}$ & $\begin{array}{c}10 \\
9 \\
1 \\
1 \\
1\end{array}$ \\
\hline Ville-Saint-Jacques & $\begin{array}{l}\text { 1, renne } \\
\text { 2, cheval } \\
3 \text {, ours } \\
4 \text {, loup } \\
5, \text { mustélidé }\end{array}$ & $\begin{array}{c}19 \\
6 \\
1 \\
1 \\
1\end{array}$ \\
\hline Verberie, niveau II.1 & \begin{tabular}{|l|} 
1, renne \\
2, cheval \\
3, spermophile \\
4, mammouth \\
\end{tabular} & $\begin{array}{c}34 \\
2 \\
1 \\
1 \\
\end{array}$ \\
\hline $\begin{array}{l}\text { Le Lagopède, } \\
\text { niveaux C1, C2, C3 }\end{array}$ & \begin{tabular}{|l|}
1, cheval \\
2, renne \\
3 , lièvre \\
4 , renard \\
5 , isatis \\
6 , faucon crécerelle \\
7, grand gravelot \\
\end{tabular} & $\begin{array}{l}2 \\
2 \\
2 \\
1 \\
1 \\
1 \\
1\end{array}$ \\
\hline Marsangy & $\begin{array}{l}\text { 1, renne } \\
\text { 2, cheval } \\
\text { 3, cerf }\end{array}$ & non disponible \\
\hline Bonnières-sur-Seine** & $\begin{array}{l}\text { 1, cheval } \\
\text { 2, mégacéros } \\
\text { 3, sanglier (intrusif ?) }\end{array}$ & non disponible \\
\hline Trou de la Marmotte & $\begin{array}{l}\text { 1, marmotte } \\
2, \text { renne } \\
3, \text { cheval } \\
4 \text {, cerf } \\
5 \text {, renard }\end{array}$ & $\begin{array}{l}10 \\
3 \\
2 \\
1 \\
1\end{array}$ \\
\hline
\end{tabular}

* Nombre minimum d'individu de fréquence (NMIf).

** Quantification impossible : tri lors des fouilles anciennes.
Tabl. IV - Données fauniques des sites magdaléniens du Bassin parisien: composition du spectre de faune et nombre minimum d'individu de combinaison (NMIc; d'après Enloe, 1997; Poplin, 1992; Schmider et al., 1995; Bignon, 2003, 2004; Bignon et al., 2006, ce volume).

cette période est maximum en raison de la raréfaction des ressources végétales.

Dans l'unité T125, les restes de faune ont été retrouvés essentiellement en association avec les pierres brûlées (Bignon et al., ibid.; Bodu et al. éd., 2006 [ce volume]). Les phases de traitement boucher qui précèdent la fracturation anthropique des os pour récupérer la moelle semblent avoir eu lieu in situ, au moins pour les segments de membres et les crânes (fig. 9). L'absence totale de parties anatomiques liées au rachis (vertèbres et côtes) pose problème dans la mesure où il pourrait s'agir du simple résultat de la fonte taphonomique. A contrario, deux arguments permettent cependant de douter de cette explication. D'abord, d'autres éléments osseux de densité minérale relativement faible (phalanges ou carpes) ont été retrouvés sur le site. Ensuite, l'unité X127, qui est sub-contemporaine de l'unité T125 (Bodu et al. éd., ibid.), témoigne du transport d'une carcasse de cheval entière sur laquelle une découpe en quartier aurait été pratiquée: la tête et les membres ont été détachés et emportés au-delà de l'unité X127. Finalement, la représentation squelettique des chevaux de l'unité T125 du niveau IV0 pourrait donc être le reflet de choix humains dans les modalités de traitements des carcasses, accentués par l'altération des témoins osseux. D'après l'indice général d'utilité du cheval (GUI; Outram, Rowley-Conwy, 1998), les 9 individus du IV0 auraient pu offrir environ $1350 \mathrm{~kg}$ de produits alimentaires, dont une partie fut vraisemblablement consommée in situ.

Le niveau IV0 témoigne de modalités cynégétiques atypiques pour le site de Pincevent, notamment en ce qui concerne la domination conjointe des rennes et des chevaux et les saisons d'occupation. En dehors de chasses a priori individuelles au cours de l'hiver, il s'agit pourtant de pratiques relativement classiques pour le Magdalénien du Bassin parisien comme nous allons le constater plus loin.

\section{TUREAU DES GARDES 10}

Situé à l'interfluve Seine-Yonne, le secteur 10 du Tureau des Gardes représente une surface de fouille de $95 \mathrm{~m}^{2}$ et s'est révélé être le plus riche en faune de tous les secteurs 
Fig. 8 - Profil d'abattage des chevaux de Pincevent, unité T125 du niveau IVO (d'après Bignon et al., 2006, ce volume).

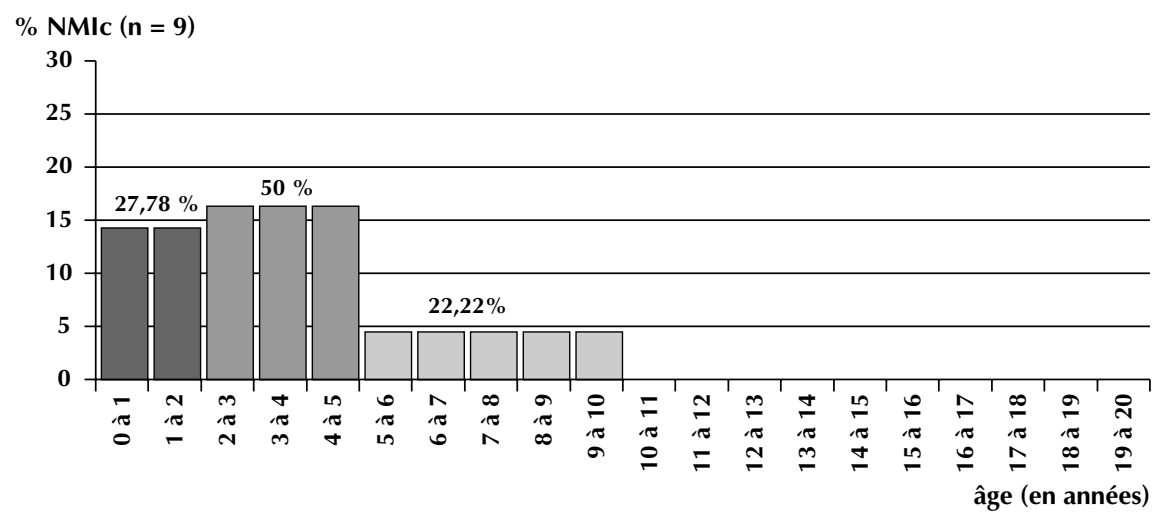

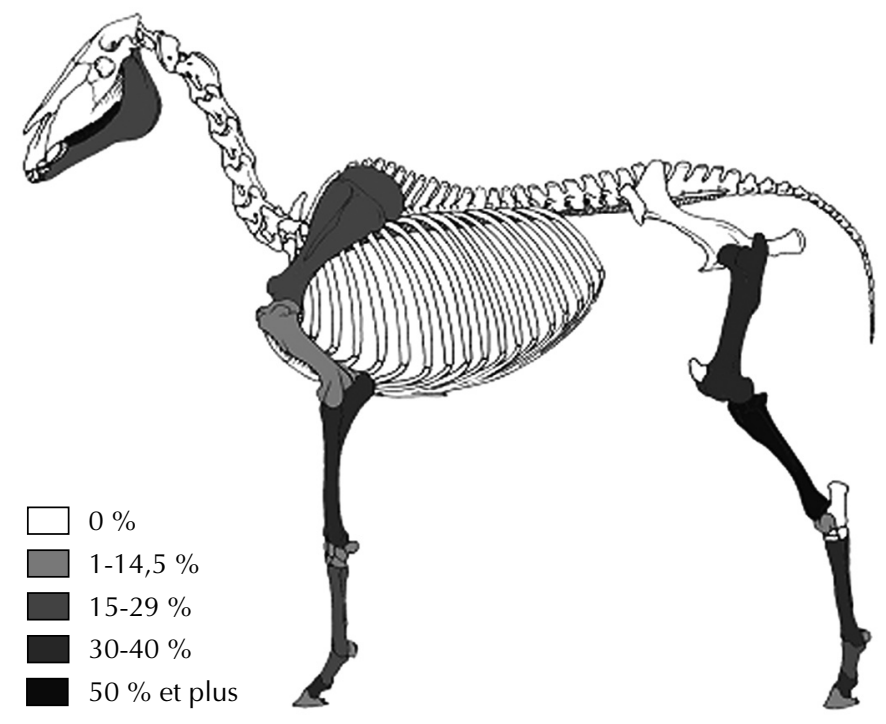

Fig. 9 - Représentation des parties squelettiques des chevaux (\% parties observées) de Pincevent, unité T125 du niveau IVO (d'après Bignon et al., 2006, ce volume).

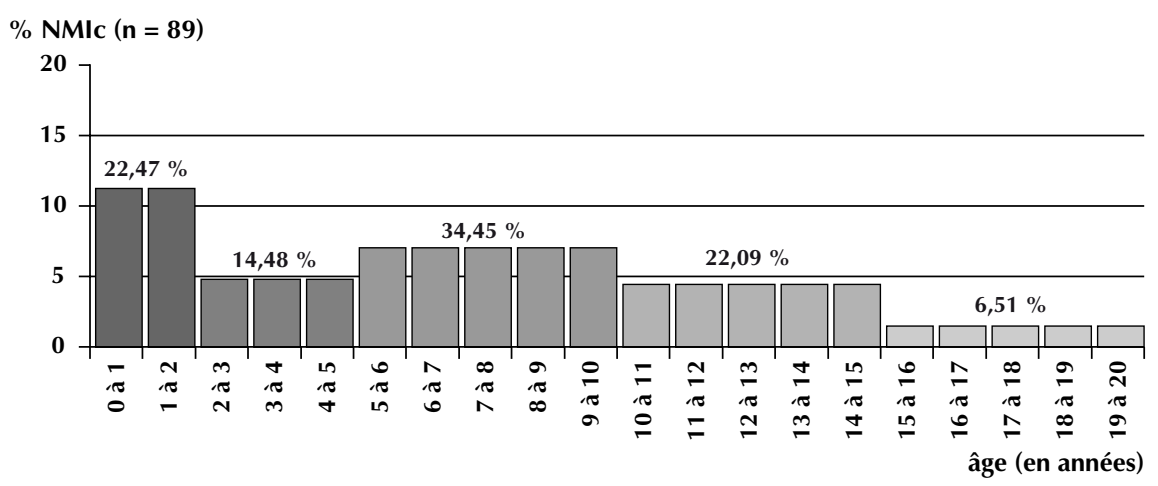

Fig. 10 - Profil d'abattage des chevaux $d u$ Tureau des Gardes, secteur 10 (d'après Bignon, 2003). 
du gisement (Bemilli, 1998; Lang, 1998). Les vestiges osseux de cheval dominent très nettement le spectre de faune (tabl. IV), devant le renne, un boviné indéterminé, le loup et le lagopède. Il est à noter qu'une phalange humaine a pu être découverte parmi les témoins fauniques (Bemilli, 1998). Des conditions taphonomiques particulières semblent avoir présidé à la conservation des vestiges fauniques. La densité des vestiges de faune fut trouvée au fond d'une cuvette remplie de sables limoneux, alors que sur les marges de celle-ci, légèrement surélevées, les sédiments étaient composés de sables fins lités (Lang, 1998). Une conservation différentielle des témoins osseux résulte de ce processus de comblement, puisque la faune est clairement mieux préservée au sein de la cuvette mais elle tend à se dégrader rapidement plus on va vers ses marges (Lang, ibid.). Ainsi, plus on s'éloigne du centre de la cuvette, plus les facteurs physico-chimiques et le weathering ont eu un impact négatif sur les ossements. L'enfouissement du niveau archéologique entre 0,30 et $1 \mathrm{~m}$ de profondeur fut en revanche très défavorable aux témoins osseux dans la mesure où l'essentiel de ceux-ci sont totalement recouverts de traces de radicelles. Ces dernières masquent de probables traces de découpe bouchère, et potentiellement l'activité des carnivores, reconnue sur seulement 4 ossements (Bemilli, 1998).

Avec 1607 éléments, les dents du secteur 10 du Tureau des Gardes représentent 38,28\% du nombre de reste déterminé et un NMIc de 89 chevaux. Les disproportions entre les dents jugales supérieures et inférieures ont conduit à sélectionner ces dernières pour construire le profil de mortalité des chevaux. Beaucoup de couronnes des dents inférieures ont été brisées, vraisemblablement comme l'a avancé F. Poplin (1992, 1994), au cours de la fracturation des corps mandibulaires pour en extraire la graisse. Le profil d'abattage obtenu montre que toutes les classes d'âge ont recueilli plusieurs individus et que les classes regroupant les plus vieux spécimens sont particulièrement bien représentées (fig. 10). Le nombre de juvéniles et de subadultes suggère que les Magdaléniens ont pris pour cible principale les groupes familiaux. Toutefois, le profil de mortalité obtenu ne correspond pas exactement au modèle de mortalité catastrophique. Les vieux et très vieux adultes (respectivement entre 10 et 15 ans et plus de 15 ans) sont légèrement surreprésentés, ce qui pourrait indiquer soit l'abattage ponctuel d'individus âgés de groupes de célibataires, soit une plus grande facilité à cibler les plus vieux animaux.

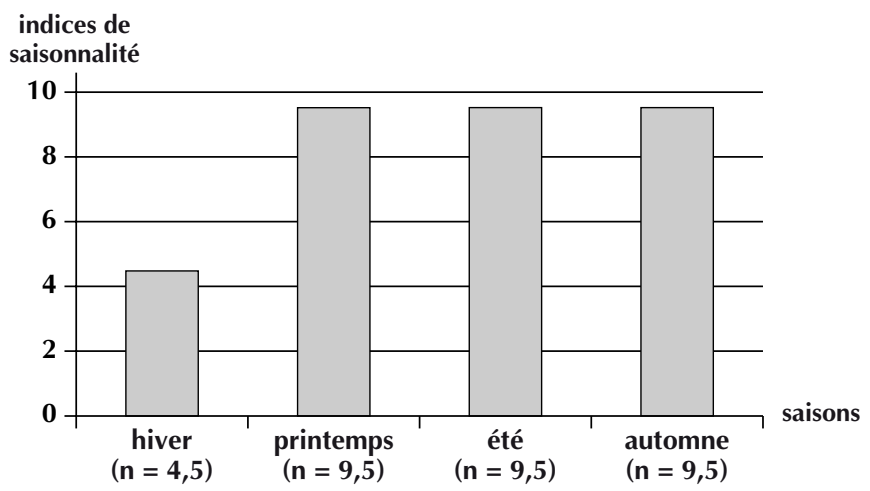

Fig. 11 - Indices de saisonnalité des chevaux du Tureau des Gardes, secteur 10 (d'après Bignon, 2003). Hiver: décembre à février inclus; printemps: mars à mai inclus; été: juin à août inclus; automne: septembre à novembre inclus.

La multiplication des épisodes de chasse doit être invoquée afin de rendre compte du nombre important de chevaux abattus sur l'occupation du secteur $10 \quad(\mathrm{n}=89)$, c'est-à-dire presque un par mètre carré fouillé. Les indices de saisonnalité du secteur 10 du Tureau des Gardes confirment que le site a été occupé par les Magdaléniens à différents moments au cours de l'année (fig. 11). La période hivernale est cependant moins bien documentée par rapport à toutes les autres saisons, ces dernières possédant par ailleurs un nombre identique d'individus. Ces indices provenant pour l'essentiel de juvéniles, il convient de remarquer que les groupes familiaux sont chassés toute l'année. Ce constat amène à considérer que les tactiques de chasse utilisées furent très vraisemblablement collectives: c'est-à-dire le rabattage et/ou l'interception des groupes familiaux, voire des groupes célibataires. À ce titre, l'interfluve Seine-Yonne est un contexte topographique et hydrographique très favorable pour limiter la fuite des bandes lors des tentatives cynégétiques. Néanmoins, si la légère surreprésentation des chevaux d'âge supérieur à 10 ans ne correspond pas aux vieilles juments des harems, l'emploi d'une chasse d'approche devrait être évoqué pour expliquer la chasse des vieux mâles célibataires, dont le caractère est plus solitaire.

Pour une partie au moins des chevaux, le traitement boucher (désarticulation, décarnisation, fracturation des os longs, conditionnement pour consommation différée) s'est déroulé entièrement sur l'occupation du secteur 10 du Tureau des Gardes. Ceci conduit à penser que le lieu d'abattage devait le plus souvent se trouver à proximité du site, de façon à limiter les efforts pour transporter les carcasses entières. D'après les analyses effectuées (Bemilli, 


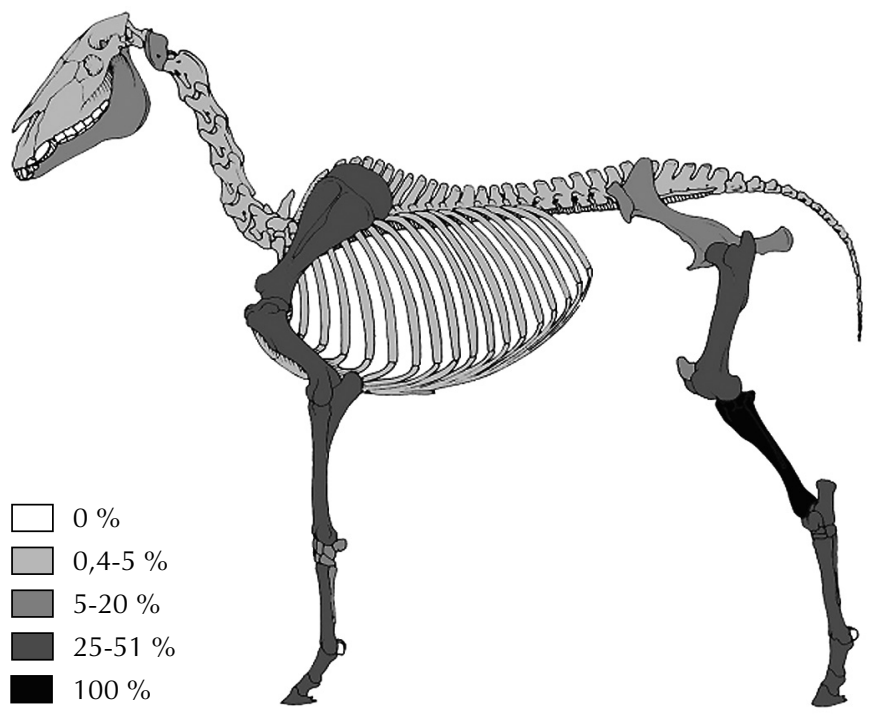

Fig. 12 - Représentation des parties squelettiques des chevaux (\% parties observées) du Tureau des Gardes, secteur 10 (d'après Bignon, 2003).

1998; Bignon, 2003), les parties squelettiques montrent un net déficit du rachis et une meilleure représentation des segments de membres (fig. 12). La conservation différentielle qui a touché la faune du secteur 10 du Tureau des Gardes a certainement eu un impact quant à la représentation des parties squelettiques. Toutefois, elle ne peut être invoquée comme unique facteur car les hommes ont également été des facteurs de destruction de la faune. En effet, les Magdaléniens ont procédé vraisemblablement à une consommation immédiate de la moelle des os longs et des abats. En outre, l'importance des pierres chauffées trouvées dans le secteur 10 (Lang, 1998) permet d'envisager que ces éléments ont servi à assurer la cuisson d'une grande quantité de parties carnées, en vue d'une consommation in situ ou différée. Ces pierres chauffées ont pu intervenir aussi dans la préparation de bouillon gras. Parmi les segments traités grâce à ces dispositifs, il est possible qu'une partie des éléments du tronc ait été préparée afin d'être transportée et consommée dans d'autres occupations, tels que des filets (quartiers de viande découpés le long de l'épine dorsale) ou contre-filets (correspondant à la région du coxal). Au total, le GUI des 89 chevaux amène à considérer que plus de 13 tonnes de viande et de moelle ont pu être tirées des équidés sur le secteur 10 du Tureau des Gardes. Le site s'apparente donc très certainement à un site de boucherie, utilisé régulièrement par les groupes magdaléniens, et où se déroulaient les premières opérations du traitement des carcasses animales en vue d'un transport des produits carnés vers d'autres occupations.

Par extension, il n'est pas sans intérêt de comparer nos résultats à ceux du secteur 2 du Grand Canton, l'autre grand site de Marolles-sur-Seine. En définitive, il ressort que les témoins des 117 chevaux retrouvés au Grand Canton peuvent être attribuables à des comportements de rejets différentiels de certaines portions de carcasses (Bridault, Bemilli, 1999). De fait, ces auteurs constatent que les portions de membres sont les plus attestées. La faible représentation du rachis et des côtes est interprétée comme un témoignage de l'emport de telles parties charnues, plutôt qu'un simple reflet d'une destruction différentielle. Cette hypothèse est soutenue par l'imposante densité des structures de combustion et le nombre impressionnant de pierres chauffées (Julien, Rieu dir., 1999), censées avoir servi à fumer les carcasses et les produits de la découpe bouchère (ces derniers sont estimés à 17,5 tonnes). Ces opérations de boucherie suggèrent une consommation immédiate de la moelle des os longs. Dans les grandes lignes, le secteur $2 \mathrm{du}$ Grand Canton permet également de penser à un site de boucherie, analogue à ce qui a pu être envisagé pour le secteur 10 du Tureau des Gardes. Les indices de saisonnalité, semblables entre ces deux sites, suggèrent la réoccupation du site toute l'année, et là encore, l'importance du nombre d'équidés abattus plaide pour l'utilisation de tactiques collectives (rabattage/ interception). La seule différence marquante réside dans le profil de mortalité du Grand Canton, essentiellement centré sur la classe d'âge des adultes (5-10 ans; Bignon, à paraître). La sélectivité des opérations cynégétiques rend toutefois moins évidente l'identification de certaines modalités: la classe d'âge des adultes n'est pas discriminante pour savoir si ce sont les harems ou bien les groupes de célibataires qui ont été pris majoritairement pour cible. La présence de quelques juvéniles témoigne que certains harems ont été touchés, mais rien ne permet d'estimer leur représentativité. En outre, l'utilisation de dispositifs techniques de type palissages ou enclos est une hypothèse qui a été formulée pour expliquer une telle sélection des adultes (Bignon, 2003, 2006).

\section{PINGEVENT IV20}

Les analyses archéozoologiques du niveau IV20 (sections 27 et 36; Enloe, 1991; David, 1994; Vigne, 1994), expriment nettement une occupation magdalénienne dans laquelle la domination du spectre faunique est assurée de façon quasi exclusive par le renne. Ce cervidé représente 
plus de $90 \%$ des restes déterminés et $86,67 \%$ du gibier abattu (avec un NMIf de 65 rennes; tabl. IV). Avec un unique individu déterminé, le cheval n'est présent qu'à hauteur de 1,33\% du NMIf, devancé par le lièvre variable (NMIf $=5$; soit 5,33\%) et le renard commun $(\mathrm{NMIf}=2$; soit 2,66\%), mais de représentation égale à celle du mammouth, du loup et de la loutre.

Grâce à un recouvrement rapide des sédiments limoneux apporté par une crue de la Seine, les témoins osseux ont été ensevelis suffisamment délicatement pour ne pas perturber les sols d'occupations magdaléniens (Leroi-Gourhan, Brézillon, 1972; Enloe, 1991; Bodu, 1993). En outre, les traces laissées habituellement par le weathering sont rares, mais ont été décelées dans les zones où les concentrations osseuses étaient les moins denses et dans les parties de l'occupation les plus surélevées (David, 1994). D'ailleurs les témoins osseux de ces dernières zones possèdent parfois des traces de radicelles, tandis qu'une dissolution légèrement plus prononcée pourrait avoir eu lieu en dehors des concentrations de l'occupation (David, ibid.). Les carnivores semblent n'avoir eu qu'un impact très superficiel sur la composition de l'assemblage faunique, au vu des rares pièces incriminées (David, ibid.). L'agent anthropique a marqué de son action technique les témoins osseux, dans la mesure où les os ont parfois servi de combustible (Wattez, 1994), où les fractures sur os frais et de nombreux points d'impact ont pu être relevés (David in Leroi-Gourhan, Brézillon, 1972; Enloe, 1991).

Peu d'informations sur les comportements magdaléniens d'acquisition des chevaux sont disponibles, car nos raisonnements ne peuvent s'appuyer que sur trois dents seulement. L'âge dentaire permet toutefois d'identifier la présence de deux individus $(\mathrm{NMIc}=2): 1$ poulain d'âge incertain (entre 1,5 et 3,5 ans) ; 1 adulte dans la force de l'âge d'environ 7-8 ans. Ce nombre d'individus montre que les activités cynégétiques relatives aux chevaux ne furent pas la priorité des Magdaléniens. S’ils ont été chassés, la tactique cynégétique employée pour abattre les équidés relèverait donc plutôt d'une chasse d'approche, individuelle ou en faible nombre pour une chasse d'interception. L'âge des chevaux du IV20 ne permet pas de savoir si les Magdaléniens ont visé un groupe familial ou un groupe de célibataires. Aucun indice de saisonnalité n'a pu être découvert du côté des équidés, mais les témoins de renne indiquent que l'occupation s'est déroulée entre septembre et octobre (Enloe, 1991, 2000a et b; David, 1994).

De même que pour la phase d'acquisition, le faible nombre des restes de chevaux $(n=33)$ limite l'interpréta-

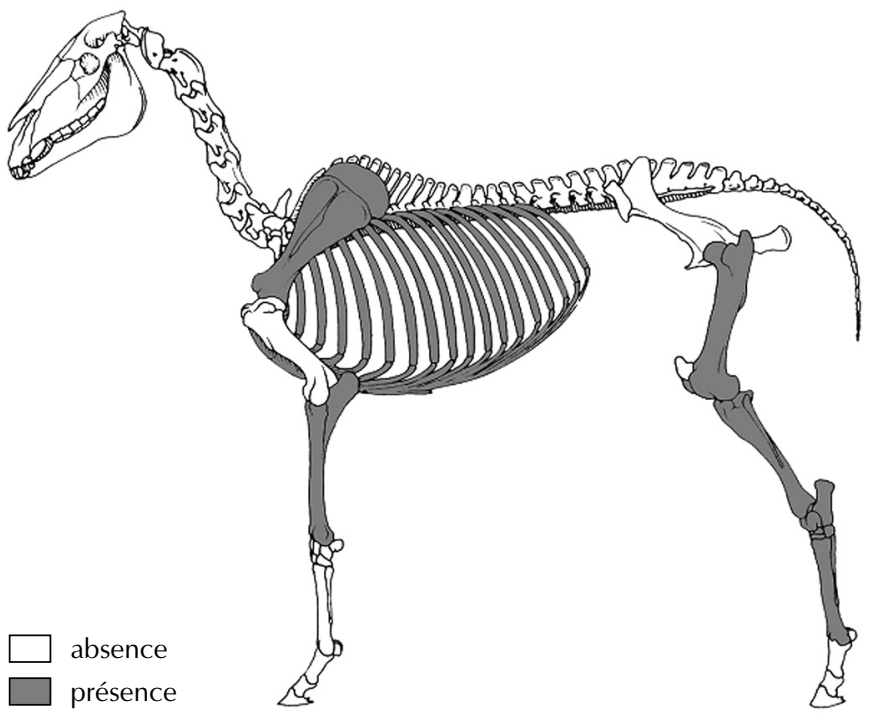

Fig. 13 - Représentation des parties squelettiques des chevaux (\% parties observées) de Pincevent, niveau IV20 (d'après Bignon, 2003).

tion du traitement boucher, comme il interdit un traitement statistique des parties anatomiques (simplement exprimées en termes de présence/absence). La figure 13 permet de remarquer l'absence presque totale des éléments de la tête et du rachis (uniquement attesté par des fragments de côte). Les rares témoins observés pour ce taxon correspondent essentiellement aux membres antérieurs et postérieurs (fortement représentés par les carpiens et les tarsiens). Ces segments anatomiques connaissent un déséquilibre dans leur latéralisation, les éléments gauches étant plus particulièrement identifiés. Ces observations suggèrent que seuls quelques segments anatomiques de cheval pourraient avoir été introduits par les Magdaléniens du niveau IV20. Il est donc raisonnable de penser que seuls ces éléments de cheval ont subi un traitement final dans l'occupation. Cette exploitation contraste grandement avec l'importance du travail dédié à l'abattage en masse des rennes et les activités liées au traitement complet de ces animaux. D'après le nombre de rennes abattus (NMIc $=77$; Enloe, comm. pers.), l'apport en nutriment des chevaux (environ $60 \mathrm{~kg}$ ) est largement éclipsé par la prise massive des rennes (3344 kg). Néanmoins, les équidés n'en demeurent pas moins la seconde source alimentaire carnée présente sur ce niveau (Bignon, 2003).

Les données fauniques conduisent à penser que ces segments de cheval pourraient avoir été rapportés initialement au début du séjour afin d'être consommés dans 


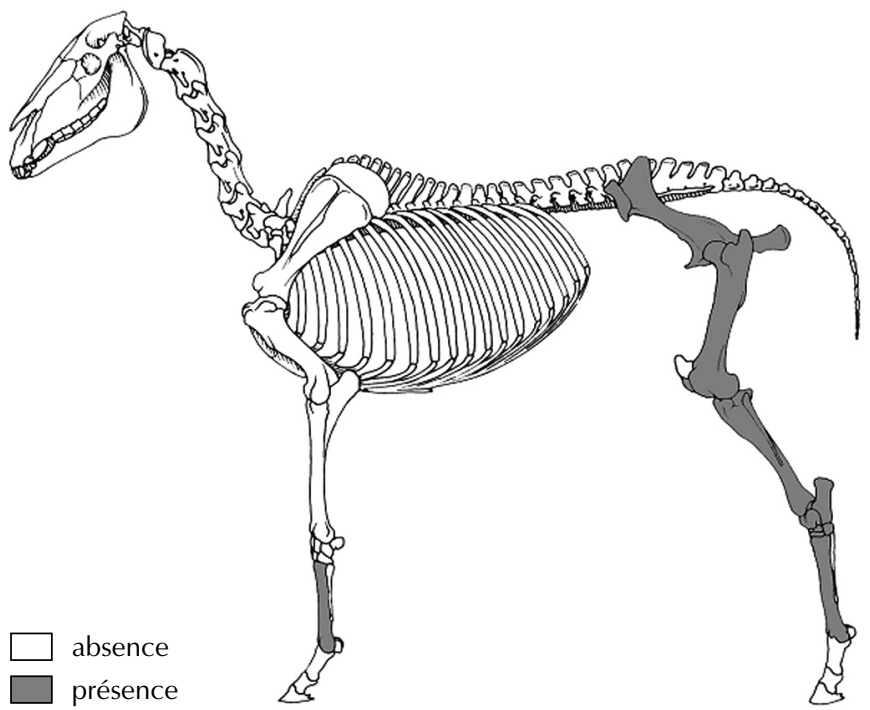

Fig. 14 - Représentation des parties squelettiques des chevaux (\% parties observées) de Verberie, niveau II.1 (d'après Bignon, 2003).

l'occupation de Pincevent. À l'appui de cette hypothèse, il semble peu probable qu'une partie des chasseurs se soit démobilisée de l'objectif cynégétique prioritaire (l'interception des rennes, engageant ainsi la survie hivernale de la communauté entière), pour se lancer à la chasse de chevaux, plus dispersés en l'automne. Ainsi, la consommation du cheval a dû se situer dans les premiers temps de l'occupation magdalénienne du niveau IV20, les autres pièces des membres manquantes ayant pu être consommés en dehors des limites du site, dans des postes d'observation, en attendant l'arrivée de la migration des rennes.

Il est remarquable que les mêmes modalités d'exploitation des chevaux ont pu être reconnues sur les niveaux archéologiques de Verberie (Le Buisson Campin), dont le spectre de faune est également dominé de manière quasi exclusive par le renne (tabl. IV; Audouze, Enloe, 1991, 2002; Enloe, Audouze, 1997; Bignon, 2003). De grandes ressemblances entre le niveau IV20 et les niveaux de Verberie sont observables, du contexte taphonomique à la faible présence du cheval dans chaque niveau (NMIf $=1$ ) et aux représentations anatomiques (essentiellement des segments de membres; fig. 14). Les hypothèses formulées pour le niveau IV20 de Pincevent sur les comportements d'acquisition, de traitement et de consommation des chevaux, doivent donc être également envisagées dans le contexte archéologique de Verberie.

\section{IMPLICATIONS POUR LES STRATÉGIES DE SUBSISTANCE ET LE MODE DE VIE}

Dans le Bassin parisien, la présence récurrente du cheval et du renne dans les spectres de faune et les modalités de leur exploitation par les Magdaléniens expriment leur rôle de proies-clés pour les stratégies de subsistance des hommes (tabl. V; Bignon, 2003). Nos analyses menées sur les équidés apportent en la matière des précisions décisives pour préciser le mode de vie de ces populations magdaléniennes.

D'emblée il nous faut constater que les Magdaléniens ont prioritairement visé les groupes familiaux. Par ailleurs, la deuxième caractéristique des tactiques magdaléniennes réside en la pratique de chasses collectives aux équidés (rabattage/interception). En effet, ces tactiques sont observées régulièrement dans les sites dominés quasi exclusivement par les chevaux et ceux à domination conjointe avec les rennes, notamment les sites de Marolles-sur-Seine. Il est donc plausible que les chasseurs magdaléniens aient cherché à optimiser les prises lors des opérations de chasse, les tactiques collectives de ces bandes furent privilégiées. De plus, si les groupes familiaux ont l'avantage pour les chasseurs d'avoir des itinéraires plus réguliers que les groupes de célibataires (Berger, 1986), d'autres aspects peuvent également être mentionnés:

- les harems sont les bandes les plus importantes en effectif;

- les chevaux sont affaiblis par les privations alimentaires et les rigueurs de la mauvaise saison;

- les poulains et les subadultes sont moins expérimentés aux dangers de la prédation et sont plus curieux;

- les juments adultes freinent les déplacements des harems les derniers mois précédant la mise bas et les premiers mois après;

- les luttes entre étalons pour le contrôle des groupes familiaux pendant la période suivante du rut, fatiguent leurs principaux défenseurs et favorisent la désorganisation des bandes; en sus, les animaux blessés peuvent être des proies faciles;

- les vieilles juments des harems sont potentiellement moins réactives aux assaillants, en dépit de leur expérience.

A contrario, dans le gisement de Verberie et le niveau VI20 de Pincevent, l'hypothèse d'une chasse de poursuite est une tactique plausible, tout comme l'éventualité d'apports de segments de membres provenant d'autres occupations. Le transport de portions carnées a pu avoir lieu entre les sites magdaléniens de Marolles-sur-Seine et de Pincevent (sur 
Tabl. V - Synthèse des données relatives à l'exploitation des chevaux dans le Bassin parisien au Magdalénien. $J=$ juvéniles; $S=$ subadultes; $A=$ adultes; $V=$ vieux adultes; $T=$ très vieux adultes; $H=$ hiver $; P=$ printemps $; E=$ été $; A=$ automne.

Coloration des saisons de chasse: noir = saison(s) unique ou principale $(s) ;$ gris = saison documentée mais secondaire.

\begin{tabular}{|c|c|c|c|c|c|c|c|}
\hline $\begin{array}{c}\text { site } \\
\text { culture }\end{array}$ & place du cheval & conservation & $\begin{array}{l}\text { profil de } \\
\text { mortalité }\end{array}$ & tactique de chasse & $\begin{array}{c}\text { saisons } \\
\text { de chasse }\end{array}$ & $\begin{array}{l}\text { phase de } \\
\text { traitement }\end{array}$ & $\begin{array}{c}\text { phase de } \\
\text { consommation }\end{array}$ \\
\hline $\begin{array}{l}\text { Pincevent IV21.3 } \\
\text { Magdalénien }\end{array}$ & $\begin{array}{l}1 / 2^{\mathrm{e}} \text { taxon ? } \\
\text { NR = environ } 25 \% \\
\text { NMlf }=2\end{array}$ & $\begin{array}{c}\text { correcte } \\
++\end{array}$ & $\begin{array}{l}\text { NMlc }=2 \\
1 \text { juvénile } \\
1 \text { adulte }\end{array}$ & $\begin{array}{l}\text { interception, poursuite?/ } \\
\text { groupes familiaux }\end{array}$ & & $\begin{array}{l}\text { segments } \\
\text { de membres }\end{array}$ & consommation in situ \\
\hline $\begin{array}{l}\text { Pincevent IV20* } \\
\text { Magdalénien }\end{array}$ & $\begin{array}{l}2^{\mathrm{e}} \text { taxon: } \\
\mathrm{NR}=2,5 \% \\
\mathrm{NMIf}=1,3 \% \\
(\mathrm{n}=1)\end{array}$ & $\begin{array}{c}\text { correcte } \\
++\end{array}$ & $\begin{array}{l}\text { NMIc }=2 \\
1 \text { juvénile } \\
1 \text { sub./adulte }\end{array}$ & \begin{tabular}{|l|} 
interception, poursuite ?/ \\
groupes familiaux
\end{tabular} & & $\begin{array}{l}\text { segments } \\
\text { de membres }\end{array}$ & consommation in situ \\
\hline $\begin{array}{l}\text { Pincevent IV0 } \\
\text { Magdalénien }\end{array}$ & $\begin{array}{l}1 \text { er taxon: } \\
\text { NR }=42,5 \% \\
\text { NMlf }=38,8 \%\end{array}$ & médiocre & $\begin{array}{l}\text { NMIC }=7 \\
\mathbf{S}_{\mathbf{A}}\end{array}$ & $\begin{array}{l}\text { interception, rabattage/ } \\
\text { groupes familiaux }\end{array}$ & & $\begin{array}{l}\text { segments } \\
\text { de membres, } \\
\text { tronc, crâne }\end{array}$ & $\begin{array}{l}\text { consommation in situ } \\
\text { et transport partiel des } \\
\text { membres? }\end{array}$ \\
\hline $\begin{array}{l}\text { Verberie II.1 à II.4 } \\
\text { Magdalénien }\end{array}$ & $\begin{array}{l}2^{\mathrm{e}} \text { taxon : } \\
\text { NR }=44 \\
\text { NMlf }=7\end{array}$ & $\begin{array}{c}\text { correcte } \\
++\end{array}$ & $\begin{array}{l}\text { II. } 1: \\
\text { NMIC }=2 \\
1 \text { subadulte } \\
1 \text { adulte }\end{array}$ & $\begin{array}{l}\text { poursuite, interception/ } \\
\text { groupes familiaux ou } \\
\text { célibataires }\end{array}$ & & $\begin{array}{l}\text { segment de } \\
\text { membres } \\
\text { (surtout } \\
\text { postérieurs) }\end{array}$ & $\begin{array}{l}\text { consommation in situ } \\
\text { et transport ponctuel } \\
\text { vers sites d'observations? }\end{array}$ \\
\hline $\begin{array}{l}\text { Étiolles, «Amas de cheval» } \\
\text { Magdalénien }\end{array}$ & $\begin{array}{l}1^{\text {er }} \text { taxon : } \\
\text { NR }=77,44 \% \\
\text { NMlf }=50 \% \\
(n=3)\end{array}$ & médiocre & $\begin{array}{l}\text { NMlc }=3 \\
1 \text { juvénile } \\
1 \text { subadulte } \\
1 \text { vieil adulte }\end{array}$ & $\begin{array}{l}\text { interception, rabattage/ } \\
\text { groupe familial }\end{array}$ & & $\begin{array}{l}\text { segments de } \\
\text { membres } \\
\text { et crânes }\end{array}$ & $\begin{array}{l}\text { consommation in situ } \\
\text { et différée (transport ?) }\end{array}$ \\
\hline $\begin{array}{l}\text { Tureau des Gardes, } \\
\text { secteur } 10 \\
\text { Magdalénien }\end{array}$ & $\begin{array}{l}1 \text { er taxon: } \\
\text { NR }=85 \% \\
\text { NMlf }=72 \% \\
(n=54)\end{array}$ & $\begin{array}{l}\text { médiocre } \\
\text { à } \\
\text { correcte }\end{array}$ & NMIC $=89$ & $\begin{array}{l}\text { rabattage, interception } \\
\text { ou piégeage/groupes } \\
\text { familiaux et célibataires }\end{array}$ & & $\begin{array}{l}\text { tous les } \\
\text { segments : } \\
++ \text { membres } \\
++ \text { crânes } \\
\end{array}$ & $\begin{array}{l}\text { consommation in situ } \\
\text { et différée. Transport } \\
\text { après traitement du } \\
\text { rachis? }\end{array}$ \\
\hline $\begin{array}{l}\text { Le Grand Canton, secteur } 2 \\
\text { Magdalénien }\end{array}$ & $\begin{array}{l}1 \text { er taxon: } \\
\text { NR }=96 \% \\
\text { NMlf }=87 \% \\
(n=117)\end{array}$ & $\begin{array}{l}\text { médiocre } \\
\text { à } \\
\text { correcte }\end{array}$ & $\begin{array}{l}\text { NMIc }=117 \\
\quad \mathbf{A}\end{array}$ & $\begin{array}{l}\text { interception, rabattage/ } \\
\text { groupes familiaux et } \\
\text { célibataires }\end{array}$ & & $\begin{array}{l}\text { tous les } \\
\text { segments : } \\
++ \text { membres } \\
++ \text { crânes }\end{array}$ & $\begin{array}{l}\text { consommation in situ } \\
\text { et différée. } \\
\text { Stockage in situ? }\end{array}$ \\
\hline
\end{tabular}

* La saisonnalité du niveau IV20 se fonde sur les seules séries dentaires de rennes.

le niveau IV20, par exemple). Cette hypothèse découle de l'adéquation avec des saisons d'occupations (notamment en automne) et du transport potentiel de segments de membres ou de rachis hors des sites de Marolles-sur-Seine. Sans être démontré, ce scénario reste plausible étant donné la proximité des gisements (distants de quelques kilomètres seulement), comme de l'importance de ceux-ci dans le système de subsistance des Magdaléniens du Bassin parisien.

Une correspondance significative existe entre les données de saisonnalité et les tactiques d'acquisition des chevaux. La chasse des groupes familiaux a été plus fréquente à la sortie de l'hiver et au printemps (fig. 15), lorsque ceux-ci étaient les plus vulnérables et les plus concentrés dans les plaines alluviales (Bignon, 2003; Bignon et al., 2006). La saison estivale, plus propice à la dispersion des bandes d'équidés dans les plaines des larges vallées, n'est attestée dans le Bassin parisien que dans les sites magdaléniens de Marolles-sur-Seine. À leur maximum pondéral à l'automne, l'importance des équidés abattus à cette période témoigne de l'intérêt alimentaire porté à ce grand gibier, malgré les difficultés liées à un espacement inter-bandes plus prononcé. L'apparente spécialisation dans l'exploitation des chevaux dans la zone de l'interfluve Yonne-Seine souligne manifestement la permanence annuelle des chevaux en ces lieux. Par ailleurs, l'originalité des morphotypes équins du Bassin parisien a été démontrée par nos études en morphométrie conventionnelle et géométrique (Bignon et al., 2006; Bignon, Eisenmann, 2006).

Additionnée à ces résultats, l'analyse des parties anatomiques permet de fonder des hypothèses sur les comportements magdaléniens, en termes de traitement et de consommation des chevaux. Le schéma opératoire est appréhendable notamment dans les sites magdaléniens dominés par les chevaux, correspondant vraisemblable- 


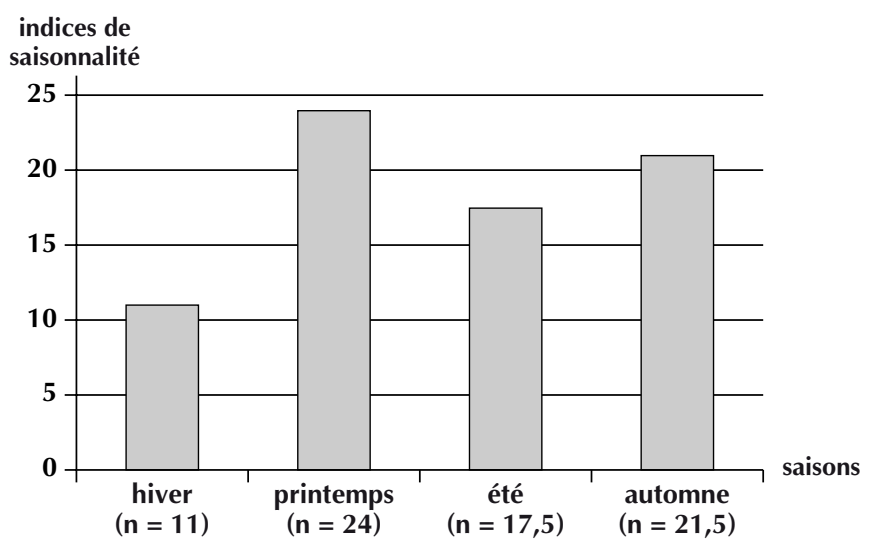

Fig. 15 - Histogramme de la totalité des indices de saisonnalités obtenus à partir des chevaux juvéniles et subadultes sur les sites magdaléniens du Bassin parisien (d'après Bignon, 2003, 2004 et Bignon et al., à paraître): Pincevent, niveaux IV21.3 et IVO; Verberie, niveau II.1; Ville-Saint-Jacques; Le Grand Canton, secteur 2; Le Tureau des Gardes, secteur 10; Étiolles, l'« amas de cheval ».

ment à des sites de boucherie. Au moins pour une partie d'entre eux les animaux y ont été rapportés entiers, afin de subir différentes étapes du traitement boucher: écorchage, désarticulation, décarnisation, exploitation de la moelle et de la graisse. L'extraction de la moelle est systématique, ce qui permet d'avancer que d'autres éléments carnés ne se conservant pas longtemps (viscères, poumons, sang, etc.), ont été consommés in situ au moment du traitement. La graisse des épiphyses, des mandibules a été également exploitée, vraisemblablement sous la forme de bouillons gras, d'où l'abondance des pierres chauffées sur les sites de Marolles-sur-Seine et Pincevent IV0. L'importance de ces témoins lithiques et des foyers pourraient également témoigner de la préparation récurrente de produits carnés en vue d'une consommation différée. L'emport de segments de membres ou de rachis d'équidé, à partir de ces sites de boucherie vers d'autres campements pour une consommation ultérieure, demeure une hypothèse parfaitement plausible également.

À partir de l'étude détaillée de l'exploitation des chevaux, il est possible de formaliser les stratégies de chasse réalisées par les Magdaléniens du Bassin parisien. Sur le plan tactique, la grande majorité des chasses du renne se caractérise par une chasse collective sur de larges troupeaux, visant un abattage massif à la sortie d'un gué (Audouze, Enloe, 1991 ; Enloe, 1991, 1997; David, 1994; Enloe, David, 1989, 1997; Enloe, Audouze, 1997). Plus rarement, une chasse plus individuelle sur des modestes groupes de rennes à d'autres saisons est documentée sur le niveau IV0 de Pincevent et au Grand Canton (Bridault, Bemilli, 1999; Bignon et al., sous presse). Les stratégies de chasse du renne s'articulent à partir des migrations automnales afin d'optimiser l'abattage sur un court laps de temps, en anticipant la régularité des routes usitées par ce taxon. Le but était certainement la constitution de réserves alimentaires pour l'hiver, ainsi qu'un approvisionnement de matières premières de qualité (bois, peaux, tendons, etc.).

En ce qui concerne les chevaux, les tactiques de chasse au Magdalénien sont très régulièrement des chasses collectives, chasse de rabattage ou d'interception, visant plus particulièrement les groupes familiaux. Dans les sites où les rennes dominent quasi exclusivement (Verberie, Pincevent), l'hypothèse de chasses individuelles a été formulée. Cependant, la possibilité d'un apport de segments de membres et de crânes provenant d'autres sites demeure tout aussi plausible. On peut aussi remarquer que le lieu d'acquisition des chevaux se situe toujours dans ou aux abords directs des grandes plaines. L'interfluve Seine-Yonne est certainement un contexte topographique et hydrographique hautement stratégique qui a facilité le conditionnement de la fuite des bandes de chevaux, lors des assauts magdaléniens. En termes de stratégies de chasse, il faut observer dès lors une récurrence des mêmes objectifs cynégétiques tout au long de l'année. Il est toutefois possible d'observer un pic à la sortie de l'hiver et au printemps, mais également un relatif désintérêt cynégétique lors la saison hivernale. Néanmoins, les chevaux sont exploités en abondance tout au long du cycle annuel et s'affirment de ce fait comme le véritable pilier des stratégies alimentaires. De plus, il est également un grand pourvoyeur de matières premières animales (peaux, crins, tendons, etc.).

Il est désormais possible d'aborder les stratégies de subsistance des Magdaléniens dans le Bassin parisien avec une documentation plus équilibrée sur les deux espècesclés. Les stratégies de subsistance des matières animales se composent majoritairement par une exploitation annuelle des chevaux, complétée par une exploitation automnale massive des troupeaux de renne. Nos résultats opèrent donc un renversement des perspectives interprétatives initiales quant à l'importance relative des rennes et des chevaux pour les Magdaléniens régionaux. En outre, il ne faudrait pas oublier le rôle conséquent joué par la diversité des espèces animales également régulièrement exploitées, mais dans une moindre mesure, dans les stratégies de chasse et de subsistance. Compte tenu des connaissances actuelles, il est frappant de retrouver dans le sous-système technique 
des matières d'origine animale, les mêmes principes organisateurs que dans le sous-système des matières lithiques taillées (Audouze et al., 1988; Julien et al., 1988; Bodu, 1993; Valentin, 1995; Pelegrin, 2000). Ainsi, l'anticipation des besoins et la recherche d'une efficacité maximale décrivent particulièrement bien les grandes tendances des stratégies cynégétiques et alimentaires, exprimant par là les connaissances éthologiques et l'organisation sociale des Magdaléniens.

Les pratiques cynégétiques révèlent des aspects cruciaux pour une meilleure appréhension du mode de vie des Magdaléniens du Bassin parisien. Les chasses de chevaux semblent avoir fait l'objet d'expéditions, relativement brèves mais répétées comme le suggèrent la densité des occupations et l'absence de structures d'habitats (Lang, 1998; Julien, Rieu dir., 1999). La répétition d'épisodes de chasses a pu aboutir à la constitution des sites très riches et étendus de Marolles-sur-Seine. La chasse aux équidés marquerait donc des sites de boucheries, intermédiaires entre les sites d'abattages et les camps de base. De même, l'acquisition des rennes renvoie à l'utilisation de tactiques de chasse collectives, au cours d'expéditions spécialisées livrant des occupations d'une durée relativement courte. Ces expéditions pourraient avoir nécessité la mobilisation d'un groupe d'hommes assez important, voire ponctuellement toute la communauté, comme cela semble être le cas pour l'occupation IV20 de Pincevent. En ce qui concerne les équidés, la tâche des chasseurs expérimentés aurait été potentiellement épaulée par une partie ou la totalité de la communauté, chargée de rabattre les bandes.

Ces observations cadrent théoriquement avec l'adoption d'un mode de vie reposant pour une grande part, sur une mobilité logistique des groupes magdaléniens. Ce mode d'organisation, souvent évoqué jusque-là par les autres sites du Bassin parisien (Pincevent, Verberie ou Étiolles notamment), peut désormais être envisagé avec plus de détails. Cependant, il reste à savoir si ces expéditions spécialisées partaient réellement d'une seule et même communauté régionale annuelle. L'alternative à cette hypothèse serait de considérer que ces épisodes de chasse émaneraient de groupes (familiaux) disjoints au cours de la bonne saison, se rassemblant ponctuellement pour réaliser des objectifs cynégétiques communs. À cela il faut ajouter que le modèle logistique magdalénien a pu être agrémenté par un réseau de caches, permettant de placer à divers endroits du territoire des réserves de nourritures. Cette option, qui semble avoir fait régulièrement partie intégrante des stratégies de subsistance des peuples nord-américains (Weniger, 1987,
1989), doit être envisagée dans le cadre du Magdalénien du Bassin parisien. En effet, certaines structures en pierre sur le site du Grand Canton pourraient bien être des caches visant à stocker au sein du territoire des réserves de nourritures (Rieu, 1999), exploitées à d'autres moments de l'année et à l'abri des prédateurs. Ce dispositif a pu être développé en cas d'urgence alimentaire éventuelle. Il aurait aussi pu permettre d'éviter les charges liées au transport, ou bien favoriser l'acheminement vers d'autres occupations en plusieurs temps des masses de produits carnées. Ces dernières atteignant tout de même plusieurs tonnes sur les sites de Marolles-sur-Seine, la question des capacités de transport et d'un potentiel réseau de cache n'est pas sans conséquences.

\section{DISCUSSION}

Dans cette sous-partie, nous procéderons à l'examen critique des modèles synchronique et diachronique et de leurs limites respectives (Bignon, 2003). Dans cette perspective, les conclusions de nos études sur l'exploitation magdalénienne des chevaux permettent d'apporter des éléments de discussion ayant fait progresser le débat.

Les données de saisonnalité obtenues à partir des chevaux montrent la récurrence des périodes pendant lesquelles se sont concentrées les expéditions cynégétiques (fig. 15): la fin de l'hiver/printemps, l'été et l'automne. Entre les activités de chasse du renne et du cheval, seule la saison automnale indique un recouvrement significatif. Loin d'apparaître comme antinomique, cette conjonction d'objectifs cynégétiques pourrait être appréhendée comme une stratégie délibérée visant à maximiser les réserves alimentaires avant l'hiver. Il n'en reste pas moins que c'est surtout la grande complémentarité de l'exploitation des rennes et des chevaux dans les stratégies de subsistance au Magdalénien qui doit être soulignée dans le cadre du Bassin parisien. Ainsi, les stratégies de subsistance des Magdaléniens dans le Bassin parisien se sont essentiellement basées sur l'exploitation des flux migratoires des animaux traversant leur territoire. Il faut considérer que la spécialisation des activités cynégétiques aux dépens des rennes et des chevaux chez les Magdaléniens du Bassin parisien n'est pas sans lien avec la composition et la structuration de l'environnement. Le "génie » de ces hommes aura été de s'appuyer sur les déplacements migratoires annuels et de trouver les ressources techniques qui ont permis d'en extraire un mode de vie. En outre, par l'exploitation conjointe de ces deux espèces-clés, le Bassin parisien n'est pas isolé en 
Europe occidentale. Les travaux de G. C. Weniger (1987, 1989) en Allemagne et dans le nord de la Suisse témoignent également de ce mode vie reposant principalement sur la chasse des rennes et des chevaux. Ce même auteur a pu mettre en lumière des variations dans les proportions respectives de ces deux taxons, à l'échelle de sites ou entre plusieurs régions allemandes. Dans une synthèse plus récente sur le Magdalénien dans différentes régions d'Allemagne (Gaudzinski, Street, 2003), il ressort que le renne est essentiellement chassé à l'automne, tandis que le cheval a été une proie recherchée à différents moments de l'année. Ces mêmes auteurs soulignent la complémentarité de ces grands gibiers, dont l'acquisition saisonnière différentielle serait fondée sur des comportements éthologiques distincts (notamment l'amplitude et la rythmicité des migrations spécifiques). Des conclusions similaires sont tirées de l'examen des sites suisses de Neuchâtel, Champréveyres et Monruz (Affolter et al., 1994; Leesch, 1997; Morel, Müller, 1997), sur lesquels notre analyse des indices de saisonnalité montre que le cheval fut l'objet de chasses répétées au cours du cycle annuel (Bignon, 2003).

Les résultats précédemment développés sur l'exploitation des chevaux du Bassin parisien illustrent également une complémentarité de la chasse des chevaux et des rennes dans les stratégies magdaléniennes. C'est donc le modèle synchronique ou de complémentarité fonctionnelle qui se trouve renforcé à l'issu de nos analyses. Au demeurant, il apparaît important d'aborder les problèmes inhérents au modèle diachronique.

Dans les faits, le modèle diachronique apparaît en contradiction avec certaines données archéologiques avérées dans les domaines d'ordre climatique, environnemental, anthropologique. Sur le plan climatique, il faut préciser qu'en dépit d'oscillations continues, le Bölling correspond à un brusque réchauffement, suivi d'une nette tendance au refroidissement, débouchant finalement sur le Dryas II (Björk et al., 1998). La seconde moitié du Bölling marque donc un retour progressif à des conditions glaciaires. D'après le modèle diachronique, l'exploitation du renne est suivie par celle du cheval au gré des changements climatiques (à l'augmentation des températures). Or, d'après ce raisonnement, les conditions climatiques auraient dû favoriser le renne plutôt que le cheval. Ce dernier est par ailleurs relativement peu sensible aux contextes écologiques froids puisqu'on les retrouve encore à l'heure actuelle en Yakoutie (Sibérie), à côté de troupeaux des rennes (Maj, 2003, 2004).
Contrairement à ce qui est sous-jacent dans la formulation du modèle diachronique, le cheval et le renne ne doivent être pas considérés comme antinomiques dans un écosystème donné. Outre le fait que ces animaux supportent des conditions périglaciaires, leurs régimes alimentaires respectifs sont suffisamment éloignés pour qu'ils n'entrent pas en compétition pour les ressources végétales (Janis, 1976; Bignon, 2003). Cette absence de rivalité écologique est illustrée dans la plupart des sites du Paléolithique supérieur en Eurasie (Hopkins et al. 1982; Guthrie, 1984, 1990; Kalhke, 1999). Dans ce cadre chrono-géographique, la «steppe à mammouth " associe systématiquement: le mammouth, le renne, le cheval et le bison. Le renne et le cheval ne sont donc pas des concurrents écologiques, comme le montrent d'ailleurs les analyses isotopiques (Drucker, 2001; Drucker et al., 2003). La présence de ces taxons renseigne plutôt sur la perpétuation de la «steppe à mammouth » au moins jusqu'à la fin du Bölling dans le Bassin parisien.

Sur le plan anthropologique, l'un des arguments importants de l'hypothèse diachronique était de postuler un changement d'ordre culturel, qui aurait accompagné le changement cynégétique du renne vers le cheval. Or, au contraire, les Magdaléniens du Bassin parisien montrent une remarquable homogénéité sur un plan technologique (Julien, Rieu dir., 1999; Bodu et al., 2006 [ce volume]). Seules apparaissent des différences dans les comportements de rejet, essentiellement liés au besoin de nombreuses pierres chauffées pour extraire la graisse contenue dans les ossements de chevaux. À cela, il faut ajouter qu'aucun site d'abattage important de renne intervenant au cours des migrations au printemps n'a été signalé dans les sites du Bassin parisien depuis 40 ans. En conséquence, il n'existe pas de témoignage attestant véritablement que le renne ait pu servir d'unique ressource animale tout au long d'un cycle annuel au Magdalénien. À cela, l'interprétation des proportions relatives des spectres en tant que le reflet exact des biomasses animales dans l'environnement nie la capacité des sociétés humaines à instaurer des "filtres de chasses ", en relation avec leurs systèmes de représentations (Lévi-Strauss, 1962; Descola, 1986, 1996; Eriksen, 1996).

Enfin, en termes de démarche méthodologique, il est difficile de concilier l'établissement d'un modèle diachronique avec le rejet des datations au radiocarbone et des données morpho-sédimentaires existantes (Pastre et al., 2000). Cependant, le modèle diachronique est intéressant dans la mesure où il pointe les limites du modèle dit synchronique, alors que l'occupation magdalénienne est 
censée avoir perduré pendant un millénaire (Valentin, Pigeot, 2000). En effet, doit-on se résoudre à une fixité hypothétique du mode de vie et des stratégies cynégétiques dans le Magdalénien du Bassin parisien?

Étant donné les fluctuations des phénomènes macroclimatiques, et les contrastes environnementaux liés aux paysages mosaïques, il est raisonnable d'admettre que certains accidents démographiques ont pu survenir ponctuellement dans les populations de rennes et de chevaux. L'instabilité climatique et écologique du Tardiglaciaire constitue, à notre sens, une des principales raisons pour que les groupes magdaléniens n'aient pas fondé de stratégies de subsistance spécialisées sur une ressource animale en particulier. En effet, ce serait prendre un risque énorme pour la survie de l'ensemble de la société, en cas d'effondrement démographique de la population animale privilégiée. Du point de vue des risques encourus, une stratégie cynégétique spécialisée sur une unique espèce animale apparaît peu compatible avec la recherche d'anticipation et d'efficacité, principes récurrents des systèmes techniques magdaléniens du Bassin parisien. Enfin, la diversification des espèces animales exploitées va également dans le sens d'une minimisation des risques cynégétiques. Cette diversification est d'ailleurs largement reconnue au Magdalénien dans différentes régions voisines, en Allemagne (Gaudzinski, Street, 2003) ou dans le Plateau suisse (Affolter et al., 1994; Leesch, 1997 ; Morel, Müller, 1997).

$$
*
$$

L'approfondissement des données sur l'exploitation du cheval par les Magdaléniens du Bassin parisien permet un changement de perspective des stratégies de chasse et de subsistance. Les résultats obtenus mettent en lumière une exploitation annuelle conséquente des chevaux, notamment les groupes familiaux. Les chasses du renne menées lors des migrations automnales apparaissent complémentaires sur le plan saisonnier. Une réelle planification des objectifs de chasse émerge de ces analyses, dans lesquelles le cheval fut le véritable pilier des stratégies de subsistance, tandis que le renne a fourni un apport alimentaire recherché pour la période hivernale. Les pratiques cynégétiques évoquent fortement le déplacement d'expéditions spécialisées (voire de la communauté entière), articulées dans une organisation sociale à mobilité logistique.

Il ressort que l'hypothèse diachronique compose avec un ensemble d'arguments non validé par les connaissances écologiques actuelles, pas plus que les données archéologiques disponibles. En revanche, ce modèle nous incite à être très attentif aux conséquences de l'instabilité climatique et aux modifications de l'environnement de l'interstade Bölling/Alleröd. Tous les résultats issus de l'exploitation des chevaux offrent des arguments supplémentaires en faveur d'une complémentarité fonctionnelle entre les différents sites magdaléniens du Bassin parisien. Cependant, les difficultés chronologiques demeurent un obstacle important à une démonstration indiscutable, tant que les méthodes de datations buteront sur le problème de plateau radiocarbone. Néanmoins, la recherche des relations fonctionnelles entre les différents gisements doit rester un cadre privilégié pour la compréhension du mode de vie magdalénien dans le Bassin parisien. En ce sens, le modèle «alternatif » proposé supra suggère une exploitation des rennes et des chevaux intégrant la dimension temporelle et l'instabilité climatoenvironnementale inhérente au Tardiglaciaire.

\section{Remerciements}

Je tiens à remercier vivement les différents responsables du PCR «Habitats et peuplements tardiglaciaires du Bassin parisien » pour leur soutien depuis tant d'années: Michèle Julien, Pierre Bodu et Boris Valentin. Je voudrais également adresser des remerciements à la Fondation des Treilles pour son aide financière postdoctorale. 


\section{BIBLIOGRAPHIE}

\section{AfFolter J., Cattin M. I., LeEsCh D., Morel P., Plumettaz N., TheW N., WENDLING G.}

1994: «Monruz, une nouvelle station magdalénienne sur les rives du lac de Neuchâtel ", Archéologie suisse, 17, n 3 p. 94-104.

Alix P., AVerbouh A., Binter L., Bodu P., Boguszewski A., COCHIN C., DELOZE V., GOUGE P., KRIER V., Leroyer C., Mordant D., PHILIPPE M., RiEU J.-L., RodRiguez P., VALENTIN B.

1993 : « Nouvelles recherches sur le peuplement magdalénien de l'interfluve Seine-Yonne: le Grand Canton et le Tureau-des-Gardes à Marolles-sur-Seine (Seine-et-Marne) ", Bulletin de la Société préhistorique française, 90, 3, p. 196-218.

AUdouze F.

1987: "The Paris Basin in magdalenian times ", in SOFFER O. (ÉD.), The Pleistocene Old World: Regional Perspectives, New York, Londres, Plenum Press, p. 183-200.

1992: «L'occupation magdalénienne du Bassin parisien ", in RIGAUD J.-P., LAVILLE H., VANDERMEERSCH B. (DIR.), Le Peuplement magdalénien. Paléogéographie physique et humaine, Actes du colloque de Chancelade, 1988, Paris, éd. du Comité des travaux historiques et scientifiques, p. $345-355$

AUdouze F., ENLOE J.-G.

1991 : «Subsistence strategies and economy in the Magdalenian of the Paris Basin, France ", in BARTON R. N. E., ROBERT A. J., ROE D. A. (DIR.), The Late Glacial in North-West Europe: Human Adaptation and Environmental Change at the End of the Pleistocene, Londres, Council for British Archaeology, British Archaeological Reports (Research Report, 77) p. $63-71$.

2002: Verberie. Le Buisson Campin (Oise), Rapport de fouilles programmées pluriannuel 2000-2002, Nanterre, Maison René-Ginouvès.

\section{Audouze F., Cahen D., Keeley L., SCHMIDER B.}

1981: «Le site magdalénien du Buisson Campin à Verberie (Oise) ", Gallia Préhistoire, 24, 1, p. 99-143.
Audouze F., Karlin C., Cahen D., Croisset E. DE, Coudret P., LARrière M., MASSON P., MAUGER M., Olive M., Pelegrin J., Pigeot N., PlisSON H., SCHMIDER B., TABORIN Y. 1988 : « Taille du silex et finalité du débitage dans le Magdalénien du Bassin parisien ", in OTTE M. (DIR.), De la Loire à l'Oder. Les civilisations du Paléolithique final dans le Nord-Ouest européen, Colloque de l'Union internationale des sciences préhistoriques et protohistoriques, Liège, 1985. Liège, Etudes et recherches archéologiques de l'université de Liège, 25 / British Archaeological Reports (International Series, 444), vol. 1, p. 55-84.

BAHN P. G.

1980 : "Crib-biting: tethered horses in the Palaeolithic?", World Archaeology, 12, 2, p. 212-217.

1984a: "Pre-Neolithic control of animals in western Europe: the faunal evidence ", in Grigson C., ClutTon-Brock J., Animals and Archaeology, Husbandry in Europe, British Archaeological Reports (International Series, 227), p. 27-34.

1984b: Pyrenean Prehistory: A Palaeoeconomic Survey of French Sites, Warminster, Aris and Philips, $511 \mathrm{p}$.

1989 : « Comments of white husbandry and herd control in the Upper Paleolithic ", Current Anthropology, 30, 5, p. 617-620.

1990 : « Motes and beams: a further response to white on the Upper Paleolithic", Current Anthropology, 31, 1, p. 71-76.

\section{BEMILLI C.}

1998: «La grande faune. Analyse préliminaire des séries des secteurs I, III, V et VI ", in LANG L., Marolles-sur-Seine: Le Tureau-des-Gardes - Vestiges dimplantations du Paléolithique supérieur, Document final de synthèse de diagnostique, Service régional de l'Archéologie d'île-deFrance, Saint-Denis / AFAN, p. 56-77.

\section{BERGER J.}

1986: Wild Horses of the Great Basin. Social Competition and Population Size, Chicago, University of Chicago Press, 326 p.

\section{BIGNON O.}

2003: Diversité et Exploitation des équidés au Tardiglaciaire en Europe occidentale Implications pour les stratégies de subsistance et les modes de vie au Magdalénien et à
l'Azilien ancien du Bassin parisien, thèse de doctorat, univ. Paris-X Nanterre.

2004: "Analyse archéozoologique du site magdalénien de Ville-Saint-Jacques - sondage "Brézillon" de 1970 ", in VALENTIN B., BODU P., JULIEN M., Habitats et peuplements tardiglaciaires $d u$ Bassin parisien - Projet collectif de recherche 2003-2005 - Rapport d'activité pour 2003, Nanterre, Maison René-Ginouvès, p. 13-21.

2006: «La chasse des chevaux au Magdalénien. Interaction chasseurs-proies et implications socio-économiques ", in SIDERA I. (DIR.), La Chasse. Pratiques sociales et symboliques, Paris, éd. De Boccard (Colloques de la Maison René-Ginouvès), p. 167-179.

Sous presse: "Approche morphométrique des dents jugales déciduales d'Equus caballus arcelini (sensu lato, Guadelli 1991) : critères de détermination et estimation de l'âge d'abattage », Compte rendu Palevol.

\section{BIGNON O., EISENMANN V.}

2006: «Western European Late Glacial Horses Diversity and its Ecological implication ", in MASHKOUR M., MEADOW R. (ÉD.), Equids in the Ancient World, Vol. III, Proceedings of $9^{\text {th }}$ ICAZ "Equid Session" (Durham, GB, August 2002), New York, Oxbow Books series, p. 161-171.

BIGNON O., BAYLAC M., VIGNE J.-D., EISENMANN V.

2006: «Geometric morphometrics and the population diversity of Late Glacial horses in Western Europe (Equus caballus arcelini) : phylogeographic and anthropological implications ", Journal of Archaeological Science, 32, p. 375-391.

Bignon O., ENloe J. G., Bemilli C.

2006: «Étude archéozoologique de l'unité T125: originalité de la chasse des rennes et des chevaux", in BODU P., Julien M., Valentin B., Debout G. (éd.), "Un dernier hiver à Pincevent: les Magdaléniens du niveau IV0 », Gallia Préhistoire, 48 [ce volume], p. 17-35.

BJÖrCK S., WAlKer M. J. C., CWYNAR L. C., JOHNSEN S., KNUDSEN K.-L., LOWE J. J., WOHLFARTH B.

1998: "An event stratigraphy for the last termination in the North Atlantic region based on the Greenland ice-core 
record: a proposal by the INTIMATE group ", Journal of Quaternary Science, 13 4, p. 283-292.

BODU P.

1993: Analyse typo-technologique du matériel lithique de quelques unités du site magdalénien de Pincevent (Seine-et-Marne). Applications spatiales, économiques et sociales, thèse de doctorat, univ. Paris-I PanthéonSorbonne, 3 vol.

\section{BODU P., JULIEN M., VALENTIN B.,} DEBOUT G. (ÉD.)

2006 : «Un dernier hiver à Pincevent. Les Magdaléniens du niveau IV0 », Gallia Préhistoire, 48 [ce volume], p. 1-160.

\section{BRIDAUlt A.}

1997: "Chasseurs, ressources animales et milieux dans le Nord de la France, de la fin du Paléolithique à la fin du Mésolithique: problématique et état de la recherche ", in FAGNART J.-P., THÉVENIN A. (DIR.), Le Tardiglaciaire en Europe du Nord-Ouest, Actes du colloque du CTHS, Amiens, 1994, Paris, éd. du Comité des travaux historiques et scientifiques, p. $165-176$

\section{Bridault A., Bemilli C.}

1999: «La chasse et le traitement des animaux ", in JULIEN M., RIEU J.-L. (DIR.), Occupations du Paléolithique supérieur dans le Sud-Est du Bassin parisien, Paris, éd. de la Maison des sciences de l'Homme (Documents d'archéologie française, 78), p. 50-64.

\section{Bridault A., Chaix L.}

2002 : « Ruptures et équilibres dans la grande faune à la fin du Pléistocène et durant l'Holocène ancien en Europe occidentale ", in Richard H., VIGNOT A. (ÉD.), Équilibre et ruptures dans les écosystèmes durant les 20 derniers millénaires en Europe de l'Ouest, Actes du colloque international de Besançon, sept. 2000, Besançon, Presses universitaires franc-comtoises (Annales littéraires, 730, série «Environnement, sociétés et archéologie »), p. 53-60.

\section{BRIDAUlt A., LANG L., RiEU J.-L.}

1996: "Occupations magdaléniennes en Bassée. Notes et informations ", Bulletin du Groupement archéologique de Seine-etMarne, 32-34, p. 289-293.

1997: "Les sites magdaléniens du Grand Canton et du Tureau des Gardes à Marolles-sur-Seine (Seine-et-Marne) », in ThÉVEnIN A., VILles A. (DIR.), Le Paléolithique supérieur de l'Est de la France: de l'Aurignacien à l'Ahrensbourgien, Actes de la table ronde de Chaumont, 1994, Reims, Mémoire de la Société archéologique champenoise, 13, p. 119-128.

\section{BRIDAULT A., BIGNON O., BEMILLI C.}

2003: «L'exploitation du cheval au Tardiglaciaire dans le Bassin Parisien ", in Costamagno S., Laroulandie V. (ÉD.), Mode de vie au Magdalénien: apports de l'archéozoologie / Zooarchaeological Insights into Magdalenian Lifeways, Actes $d u$ XIV congrès UISPP, Université de Liège, 2-8 sept. 2001, Colloque/Symposium 6.4, Oxford, Archaeopress, British Archaeological Report (International Series S1144), p. 33-45.

\section{Charles R.}

1998 : Late magalenian chronology and faunal exploitation in the North-Western Ardennes, Oxford, British Archaeological Reports (International Series, 737).

\section{COOPE G. R., LEMDAHL G., LOWE J. J.,} WALKLING A.

1998: « Temperature gradients in Northern Europe during the last glacial-Holocene transition (14-9 ${ }^{14} \mathrm{C}$ kyr BP) interpreted from coleopteran assemblages ", Journal of Quaternary Science, 13, 5, p. 419-433.

\section{COUDRET P., LAPIERRE-CABIRAN M.,}

Olive M., Pigeot N., TABorin Y.

1994 : "Étiolles", in TABORIN Y. (DIR.), Environnements des habitats magdaléniens dans le centre du Bassin parisien, Paris, éd. de la Maison des sciences de l'Homme (Documents d'archéologie française, 43), p. 132-146.

\section{Costamagno S.}

1999 : Stratégies de chasse et fonction des sites au Magdalénien dans le Sud de la France, thèse de doctorat en Préhistoire et Géologie du Quaternaire, univ. Bordeaux-I.

DAVID F.

1994 : « La faune de mammifères de Pincevent et de Verberie ", in TABORIN Y. (DIR.), Environnements et habitats magdaléniens dans le centre du Bassin parisien, Paris, éd. de la Maison des sciences de l'Homme (Documents d'archéologie française, 43), p. 105-110.

\section{DESCOLA P.}

1986 : La Nature domestique. Symbolisme et praxis dans l'écologie des Achuars, Paris, éd. de la Maison des sciences de l'Homme.

1996 : « Les cosmologies des Indiens d'Amazonie », La Recherche, 292, p. 62-67.

\section{DJINDJIAN F.}

2000: "Identité, chronologie et territoires du Magdalénien en Europe occidentale: questions posées ", in PION G., Le Paléolithique supérieur récent: nouvelles données sur le peuplement et l'environnement, Actes de la table ronde de Chambéry, Paris, Société préhistorique française (Mémoires de la SPF, XXVIII), p. 95-112.

\section{DRUCKER D.}

2001: Validation méthodologique de l'analyse isotopique d'ossements fossiles et apports aux reconstructions paléoécologiques $d u$ Paléolithique supérieur du Sud-Ouest de la France, thèse de doctorat en Géochimie, univ. Paris-VI Pierre et Marie Curie.

DRUCKER D., BOCHERENS H., BILLIOU D.

2003 : « Evidence for shifting environmental conditions in Southwestern France from 33000 to 15000 years ago derived from carbon-13 and nitrogen-15 natural abundances in collagen of large herbivores ", Earth and Planetary Science Letters, 216, p. 163-173.

\section{DUNCAN P.}

1992: Horses and Grasses. The Nutritional Ecology of Equids and their Impact on the Camargue, New York, Springer-Verlag, $287 \mathrm{p}$.

ENLOE J. G.

1991: Subsistence Organization in the Upper Paleolithic: Carcass Refitting and Food Sharing at Pincevent, Doctoral dissertation, University of New Mexico.

1994: «Comparaison entre les troupeaux de rennes de Pincevent et de Verberie ", in TABORIN Y. (DIR.), Environnements et habitats magdaléniens dans le centre du Bassin parisien, Paris, éd. de la Maison des sciences de l'Homme (Documents d'archéologie française, 43), p. 115-117.

1997: «Seasonality and age structure in remains of Rangifer tarandus: Magdalenian hunting strategy at Verberie ", Anthropozoologica, 25-26 (Actes $\mathrm{du}$ colloque international d'archéozoologie, Konstanz, 26 sept.-01 oct. 1994), p. 95-102.

2000a: "Le Magdalénien du Bassin parisien au Tardiglaciaire: la chasse aux rennes comparée à celle d'autres espèces ", in PION G. (DIR.), Le Paléolithique supérieur récent: nouvelles données sur le peuplement et l'environnement, Actes de la table ronde de Chambéry, 12-13 mars 1999, Paris, Société préhistorique française (Mémoires de la SPF, XXVIII), p. 39-45. 
2000b: «Readaptation: changes in Magdalenian subsistence and social organization, in PETERKIN G. L., PRICE H. A. (ÉD.), Regional Approaches to Adaptation in Late Pleistocene Western Europe, Oxford, British Archaeological Reports (International Series, 896), p. $115-120$

2000c: "Chasse au cheval dans le Bassin parisien », La Recherche, 332, p. 20-22

ENLOE J. G., AUdOUZE F.

1997: "Le rôle de l'environnement dans la vie des chasseurs magdaléniens du Bassin parisien ", in FAGNART J.-P., THÉVENIN A. (DIR.), Le Tardiglaciaire en Europe du Nord-Ouest, Actes du colloque du CTHS, Amiens, 1994, Paris, éd. du Comité des travaux historiques et scientifiques, p. $177-186$

\section{ENLOE J. G., DAVID F.}

1989 : « Le remontage des os par individus: le partage du renne chez les Magdaléniens de Pincevent (La Grande-Paroisse, Seineet-Marne) ", Bulletin de la Société préhistorique française, 86, 9, p. 275-281.

1997: «Rangifer herb behavior: Seasonality of hunting in the Magdalenian of the Paris Basin) ", in JACKSON L. J., ThaCKer P. T., Caribou and Reindeer Hunters of the Northern Hemisphere, Brookfiels, Avebury Press (Worldwide Archaeology Series, 6), p. 52-68.

\section{ERIKSEN B. V.}

1996 : « Resource exploitation, subsistence strategies, and adaptiveness in late Pleistocene-early Holocene Northwest Europe ", in STRAUS L. G., ERIKSEN B. V., ERLANDSON J. M., YESNER D. R., Humans at the End of the Ice Age: The Archeology of the Pleistocene-Holocene Transition, New York, Londres, Plenum Press, p. 101-128.

\section{FONTANA L.}

1998: Mobilité et subsistance au Magdalénien dans le Languedoc occidental et le Roussillon, thèse de doctorat, univ. Paris-I PanthéonSorbonne.

2000 : « La chasse au renne au Paléolithique supérieur dans le Sud-Ouest de la France: nouvelles hypothèses de travail ", Paléo, 12 , p. $141-164$

\section{GAUDZINSKI S., STREeT M.}

2003 : «Reconsidering hunting specialisation in the German magdalenian faunal record ", in COSTAMAGNO S. Laroulandie V. (éd.), Mode de vie au Magdalénien: apports de l'archéozoologie / Zooarchaeological insights into Magdalenian lifeways, Actes du XIV congrès UISPP, Université of Liège, 2-8 sept. 2001, Colloque / Symposium 6.4, Oxford, Archaeopress, British Archaeological Report (International Series S1144), p. 11-21.

\section{GUTHRIE R. D.}

1982 : "Mammals of the mammoth steppe as paleoenvironmental indicator », in HOPKINS D. M., MATTHEWS JR. J. V., SCHWEGER C. E., YOUNG S. B. (ÉD.), Paleoecology of Beringia. New York, Londres, Academic Press, p. 307-328.

1984: "Mosaïcs, allelochemics and nutrients. An ecological theory of late Pleistocene megafaunal extinctions ", in MARTIN P. S., KLEIN R. G. (ÉD.), Quaternary Extinctions - A Prehistoric Revolution. Arizona, University of Arizona Press, p. 259-298.

1990 : Frozen Fauna of the Mammoth Steppe: the Story of the Blue Babe, Chicago, University of Chicago Press, 323 p.

\section{HOPKINS D. M., MATTHEWS J. V. JR,}

SCHWEGER S. B., YOUNG S. B.

1982: Paleoecology of Beringia, New York, Academic Press, 489 p.

JANIS C. M.

1976: «The evolutionary strategy of the Equidae and the origins of rumen and cecaldigestion ", Evolution, 30, p. $757-774$

JULIEN M., RIEU J.-L. (DIR.)

1999: Occupations du Paléolithique supérieur dans le Sud-Est du Bassin parisien, Paris, éd. de la Maison des sciences de l'Homme (Documents d'archéologie française, 78, 235 p.).

JUlien M., AUdOUZE F., BAFFIER D., BODU P., COUdRet P., DAVID F., GAUCHER G., KARLIN C., LARRIÈRE M., MASSON P., OLIVE M., ORLIAC M., PIGEOT N., RIEU J.-L., SCHMIDER B., TABORIN Y.

1988: «Organisation de l'espace et fonction des habitats magdaléniens du Bassin parisien », in OTTE M. (DIR.), De la Loire à l'Oder. Les civilisations du Paléolithique final dans le Nord-Ouest européen, Actes du colloque de l'Union internationale des sciences préhistoriques et protohistoriques, Liège, 1985, Oxford, British Archaeological Reports (International Series, 444), Liège, Études et Recherches archéologiques de l'université de Liège, 25, vol. 1, p. 85-123.

KALHKE R.-D.

1999: The history of the origin, evolution and dispersal of the Late Pleistocene MammuthusCoelodonta faunal complex in Eurasia (large mammals), Rapid City, Mammoth Site of Hot Spring, 219 p.

LANG L.

1998 : Marolles-sur-Seine: Le Tureau-des-Gardes - Vestiges d'implantations du Paléolithique supérieur, Document final de synthèse de diagnostique, Service régional de l'Archéologie d'Île-de-France, SaintDenis / AFAN.

\section{LEESCH D.}

1997: Hauterive-Champréveyres, 10. Un campement magdalénien au bord du lac de Neuchâtel: cadre chronologique et culturel, mobilier et structures (secteur 1), Neuchâtel, Musée cantonal d'archéologie (Archéologie neuchâteloise, 19).

\section{LEROI-GOURHAN A., BRÉZILlON M.}

1972 : Fouilles de Pincevent: essai d'analyse ethnographique d'un habitat magdalénien (la section 36), Paris, éd. du CNRS (Suppl. à Gallia Préhistoire, VII).

\section{LEVINE M.-A.}

1979 : Archaeo-zoological analysis of some Upper Pleistocene horse bone assemblages in Western Europe, Ph D. Thesis, University of Cambridge.

1983 : « Mortality models and the interpretation of population horse structure ", in BAILEY G. N. (ÉD.), Hunter-Gatherers Economy in Prehistory, Cambridge, Cambridge University Press, p. 23-46.

2003: «The origins of horse husbandry on the eurasian steppe ", in LEVINE M., RASSAMAKIN Y., KISLENKO A., Tatarintseva N., Late Prehistoric Exploitation of the Eurasian Steppe, Cambridge, McDonald Institute for Archaeological Research, p. 5-58.

\section{LeVi-STRAUSS C.}

1962, réed. 1992: La Pensée sauvage, Paris, Plon (Presses Pocket/Agora), 352 p.

\section{MAGNY M.}

1995: Une Histoire du climat, des derniers mammouths au siècle de l'automobile, Paris, éd. Errance (Coll. des Hespérides), $173 \mathrm{p}$.

MAJ E.

2003 : Ethnoequid-Mission en Iakoutie, Rapport scientifique, Programme de recherche Institut Paul-Émile Victor, 2003-2004, Paris, $66 \mathrm{p}$.

2004 : Ethnoequid-Mission en Iakoutie, Rapport scientifique, Programme de recherche 
Institut Paul-Émile Victor, campagne été 2004, Paris, 118 p.

\section{MOREL P., MÜLLER W.}

1997: Hauterive-Champréveyres, 11. Un campement magdalénien au bord du lac de Neuchâtel: étude archéozoologique (secteur 1), Neuchâtel, Musée cantonal d'archéologie (Archéologie neuchâteloise, 23).

\section{OLIVE M.}

1988 : Une Habitation magdalénienne d'Étiolles: l'unité P15, Paris, Société préhistorique française (Mémoires de la SPF, XX), 2 vol.

\section{Olive M., AUdouze F., JULIEN M.}

2000 : « Nouvelles données concernant les campements magdaléniens du Bassin parisien ", in VALENTIN B., BODU P., CHRISTENSEN M. (DIR.), L'Europe centrale et septentrionale au Tardiglaciaire, Actes de la table ronde internationale de Nemours (14-16 mai 1997), Nemours, éd. APRAIF (Mémoire du musée de Préhistoire d'Îlede-France, 7), p. 89-304

\section{OSWALT W. H.}

1976 : An AnthropologicalAnalysis of Food-Getting Technology, New York, Wiley, 328 p.

\section{OTTE M.}

1992 : «Processus de diffusion à long terme au Magdalénien ", in RIgAUd J.-P., LAVILLE H., VANDERMEERSCH B. (DIR.), Le Peuplement magdalénien. Paléogéographie physique et humaine, Actes du colloque de Chancelade, 1988, Paris, éd. du Comité des travaux historiques et scientifiques, p. $399-416$.

\section{OUTRAM A., ROWLEY-CONWY P.}

1998: « Meat and marrow utility indices for horse (Equus) ", Journal of Archaeological Science, 25, p. 839-849.

PASTRE J.-F., LEROYER C., LIMONDINLozouet N., Chausse C., Fontugne M., GebHaRdT A., HATTE C., KRIER V.

2000: «Le Tardiglaciaire des fonds de vallée du Bassin parisien (France)", Quaternaire, 11, 2, p. 107-122.

\section{PELEGRIN J.}

2000: «Les techniques de débitage laminaire au Tardiglaciaire: critères de diagnose et quelques réflexions ", in VAlentin B., Bodu P., Christensen M. (DIR.), L'Europe centrale et septentrionale au Tardiglaciaire, Actes de la table ronde internationale de Nemours (14-16 mai 1997), Nemours, éd. APRAIF, (Mémoire du musée de Préhistoire d'Île-de-France, 7) p. 73-86.

\section{Pigeot N.}

1987: Magdaléniens d'Étiolles. Économie de débitage et organisation sociale (l'unité d'habitation U5), Paris, éd. du CNRS (Suppl. à Gallia Préhistoire, XXV).

PIGEOT N. (DIR.)

2004: Les Derniers Magdaléniens d'Étiolles: perspectives culturelles et paléohistoriques. Paris, CNRS Éditions (Suppl. à Gallia Préhistoire, XXXVII).

\section{POPLIN F.}

1992: «Les restes osseux animaux de l'habitat magdalénien de Marsangy ", in SCHMIDER B. (DIR.), Marsangy, un campement des derniers chasseurs magdaléniens sur les bords de l'Yonne, Liège, Études et recherches archéologiques de l'université de Liège, 55, p. 37-44.

1994 : «La faune d'Étiolles: milieu animal, milieu taphonomique, milieu humain », in TABORIN Y. (DIR.), Environnements des habitats magdaléniens dans le centre $d u$ Bassin parisien, Paris, éd. de la Maison des sciences de l'Homme (Documents d'archéologie française, 43), p. $94-104$

RIEU J.-L.

1999 : «Les foyers et les pierres chauffées ", in JULIEN M., RIEU J.-L. (DIR.), Occupations du Paléolithique supérieur dans le Sud-Est $d u$ Bassin parisien, Paris, éd. de la Maison des sciences de l'Homme (Documents d'archéologie française, 78), p. 95-102.

\section{RIGAUD J.-P., LAVILLE H.,}

VANDERMEERSCH B.

1992: Le Peuplement magdalénien. Paléogéographie physique et humaine, Actes du colloque de Chancelade, 1988, Paris, éd. du Comité des travaux historiques et scientifiques.

SChMider B., VALENTIN B., BAFFiER D., DAVID F., JULIEN M., LEROI-

Gourhan ARL., MOURER-ChaUviré C., POUlaIN T., Roblin-JOUVE A.,

TABORIN Y.

1995 : «L'abri du Lagopède (fouilles LeroiGourhan) et le Magdalénien des grottes de la Cure ", Gallia Préhistoire, 37, p. 55-114.

STUIVER M., Grootes P., BraziUnas T. 1995: " The GISP2 $\delta^{18} \mathrm{O}$ climate record of the past 16,500 years and the role of the sun, ocean, and volcanoes ", Quaternary Research, 44, p. 341-354
STUIVER M., ReIMER P., BraziUnAS T.

1998: «High-precision radiocarbon age calibration for terrestrial and marine samples ", Radiocarbon, 40, 3, p. 11271151.

\section{TRESSET A.}

1996 : Le Rôle des relations homme/animal dans l'évolution économique et culturelle des sociétés des $V^{e}$ et $I V^{e}$ millénaires en Bassin parisien, thèse de doctorat, univ. Paris-I PanthéonSorbonne.

\section{VALENTIN B.}

1995: Les Groupes humains et leurs traditions au Tardiglaciaire dans le Bassin parisien. Apports de la technologie comparée, thèse de doctorat, univ. Paris-I PanthéonSorbonne, 3 vol.

\section{Valentin B., Pigeot N.}

2000: «Éléments pour une chronologie des occupations magdaléniennes dans le Bassin parisien ", in VALENTIN B. BOdu P., CHRISTENSEN M. (DIR.), L'Europe centrale et septentrionale au Tardiglaciaire, Actes de la table ronde internationale de Nemours (14-16 mai 1997), Nemours, éd. APRAIF (Mémoire du musée de Préhistoire d'île-de-France, 7), p. $129-138$

VIGNE J.-D.

1994: "Les rongeurs de la section 36 de Pincevent », in TABORIN Y., Environnements des habitats magdaléniens dans le centre du Bassin parisien, Paris, éd. de la Maison des sciences de l'Homme (Documents d'archéologie française, 43), p. 111-119.

1998: «Faciès culturels et sous-système technique de l'acquisition des ressources animales. Application au Néolithique ancien méditerranée », in D'ANNA A., BINDER D. (ÉD.), Production et identitéculturelle, Rencontres méridionales de Préhistoire récente, Arles, 1996, Antibes, éd. APDCA, p. $27-45$.

\section{VOORHIES M.-R.}

1969: Taphonomy and Population Dynamics of an Early Pliocene Vertebrate Fauna, Knox County, Nebraska, Contribution to Geology, special paper $n^{\circ} 1$, Laramie, University of Wyoming.

\section{WATTEZ J.}

1994: "Micromorphologie des foyers d'Étiolles, de Pincevent et de Verberie », in TABORIN Y. (DIR.), Environnements des habitats magdaléniens dans le centre du Bassin parisien, Paris, éd. de la Maison des 
sciences de l'Homme (Documents d'archéologie française, 43), p. 111-119.

\section{WEINSTOCK J.}

1997: «Late Paleolithic reindeer populations in Central and Western Europe », in KOKABI M., WAHL J. (ÉD.),
Anthropozoologica, 25-26 (Actes du colloque international d'archéozoologie, Konstanz, 26 sept.-1 ${ }^{\text {er }}$ oct. 1994), p. $383-388$.

WENIGER G. C.

1987 : «Magdalenian settlement and sub- sistence in South-West Germany ", Proceedings of the Prehistoric Society, 53, p. 293-307.

1989 : « The Magdalenian in Western Central Europe: settlement pattern and regionality ", Journal of World Prehistory, 3, 3, p. $323-372$. 